\title{
A Mechanistic Thermal Fatigue Model for SnAgCu Solder Joints
}

\author{
PETER BORGESEN,${ }^{1,2,5}$ LUKE WENTLENT, ${ }^{2}$ SA'D HAMASHA, ${ }^{3}$ \\ SAIF KHASAWNEH ${ }^{1}$ SAM SHIRAZI,${ }^{1}$ DEBORA SCHMITZ ${ }^{1}$ \\ THAER ALGHOUL, ${ }^{1}$ CHRIS GREENE, ${ }^{1}$ and LIANG YIN $^{4}$
}

1.-Department of Systems Science and Industrial Engineering, Binghamton University, P.O. Box 6000, Binghamton, NY 13902, USA. 2.-Materials Science Program, Binghamton University, P.O. Box 6000, Binghamton, NY 13902, USA. 3.-Department of Industrial and Systems Engineering, Auburn University, Auburn, AL 36849, USA. 4.-GE Global Research, Niskayuna, NY 12309, USA. 5.-e-mail: pborgese@binghamton.edu

The present work offers both a complete, quantitative model and a conservative acceleration factor expression for the life span of $\mathrm{SnAgCu}$ solder joints in thermal cycling. A broad range of thermal cycling experiments, conducted over many years, has revealed a series of systematic trends that are not compatible with common damage functions or constitutive relations. Complementary mechanical testing and systematic studies of the evolution of the microstructure and damage have led to a fundamental understanding of the progression of thermal fatigue and failure. A special experiment was developed to allow the effective deconstruction of conventional thermal cycling experiments and the finalization of our model. According to this model, the evolution of damage and failure in thermal cycling is controlled by a continuous recrystallization process which is dominated by the coalescence and rotation of dislocation cell structures continuously added to during the hightemperature dwell. The dominance of this dynamic recrystallization contribution is not consistent with the common assumption of a correlation between the number of cycles to failure and the total work done on the solder joint in question in each cycle. It is, however, consistent with an apparent dependence on the work done during the high-temperature dwell. Importantly, the onset of this recrystallization is delayed by pinning on the $\mathrm{Ag}_{3} \mathrm{Sn}$ precipitates until these have coarsened sufficiently, leading to a model with two terms where one tends to dominate in service and the other in accelerated thermal cycling tests. Accumulation of damage under realistic service conditions with varying dwell temperatures and times is also addressed.

Key words: Reliability, thermal cycling, model, acceleration factor, solder

\section{INTRODUCTION}

In the absence of avoidable defects, the ultimate life span of many microelectronics products is limited by failure of the solder joints due to overstress or fatigue. Portable applications of highend microelectronics are becoming ever more common, but thermal fatigue remains a common concern. Traditionally, thermal fatigue life in service

(Received September 3, 2017; accepted February 1, 2018; published online February 15, 2018) concerns have most often focused on the solder joint configurations associated with area array assemblies such as ball grid arrays (BGAs), chip-scale packages (CSPs), land grid arrays (LGAs) and sometimes flip chips, although other assembly types may fail faster in a particular product. ${ }^{1}$ The assessment of thermal cycling performance is commonly done by accelerated testing together with modelbased interpretation of the results in terms of the effects of thermal excursions in long-term service. Importantly, this is also the implicit assumption behind a reliance on industry consensus or standards to ensure sufficient reliability. We have, 
however, shown the most common acceleration factor expressions and damage functions for thermal cycling to deviate systematically from observed dependencies on cycling parameters ${ }^{2,3}$ and we argue that they are not mechanistically justifiable when it comes to tin-silver-copper ( $\mathrm{SnAgCu}$ ) solder joints.

Most current models were developed for tin-lead $(\mathrm{SnPb})$ solder joints and more recently adapted to lead-free solders, usually by 'fitting' the predictions to accelerated test data to extract new values for the various constants. The problem with this, when it comes to extrapolating accelerated test results to 'life in service', is that most available data sets contain only a very limited number of data for a specific combination of component, printed circuit board (PCB), pad design and finishes, and process parameters. We may, therefore, end up with a reasonably good empirical fit to dependencies on these factors under accelerated test conditions. However, the dependencies on cycling parameters, which are what we need for the extrapolations to service conditions, cannot actually be validated by a comparison between life in, say, two accelerated tests. We have therefore taken the opposite approach of varying cycling parameters across ranges as broad as possible for specific combinations of components, PCBs, pad design and finishes, and process parameters.

A preceding paper ${ }^{3}$ relied primarily on different sets of thermal cycling data that show the effects of varying the dwell times while keeping design, materials, process and remaining test parameters fixed. The inability of the most common thermal cycling models to account for the systematic effects of dwell time shows that there cannot be a valid mechanistic justification for any of them when it comes to $\mathrm{SnAgCu}$ solder joints, and indeed they are not compatible with our current mechanistic understanding of damage evolution and failure. The models considered included the so-called Engelmaier model and modifications of the NorrisLandzberg acceleration factor expression as well as damage functions based on scaling with the rate of inelastic energy deposition (work) or the entropy change.

The present work documents a mechanistic understanding based on detailed studies of the microstructural evolution in cycling together with a variety of systematic test results from both thermal and isothermal cycling experiments. This is focused on $\mathrm{SnAgCu}$ solder joints with either a single Sn grain or a cyclically twinned 'beach ball' structure (Fig. 1). Each realistic area array joint is invariably the result of a single solidification event during cool-down from reflow, leading to a cyclically twinned Sn structure with no weak, high-angle grain boundaries. ${ }^{4}$ The twin boundaries in Fig. 1 are not preferred paths for crack propagation. Instead, failure in thermal cycling almost always occurs by recrystallization of the $\mathrm{Sn}$ to form a network of high-angle grain boundaries across the joint ${ }^{5-10}$, followed by cracking along these boundaries. $^{11-13}$ It is our belief that the general picture below can be extended to explain the superior performance of a so-called interlaced twinning structure ${ }^{14}$ but that may require more work.

The most credible approaches to quantitative modeling rely on the finite element modeling (FEM)-based calculation of stresses and strains, and often other factors derived from these (work, entropy, etc.), versus time and temperature in cycling. ${ }^{15-19}$ The results are combined with a damage function to predict the ongoing evolution of damage and failure. Our overall work is focused on this kind of approach. We emphasize that our damage function is intended for use in conjunction with accelerated test results to extrapolate these to a value for 'life in service'. It is, of course, critical for this kind of approach that damage mechanisms be the same in the accelerated test as in service. A recent paper $^{20}$ reported an absence of significant recrystallization in a particular assembly after failure under sufficiently low-strain cycling conditions. On the other hand, an International Electronics Manufacturing Initiative (iNEMI) project cycled different assemblies for 2 years under conditions representative of realistic service conditions, and failure was clearly preceded by major recrystallization. ${ }^{21}$ As argued below, we believe this to be a result of a competition between two different damage mechanisms that depend extremely differently on cycling parameters, and work is ongoing to address the first case based on our evolving understanding of transgranular crack growth in isothermal cycling. The present work is focused on all the cases where failure involved recrystallization.

A practical model is presented, allowing the application of accelerated thermal cycling test

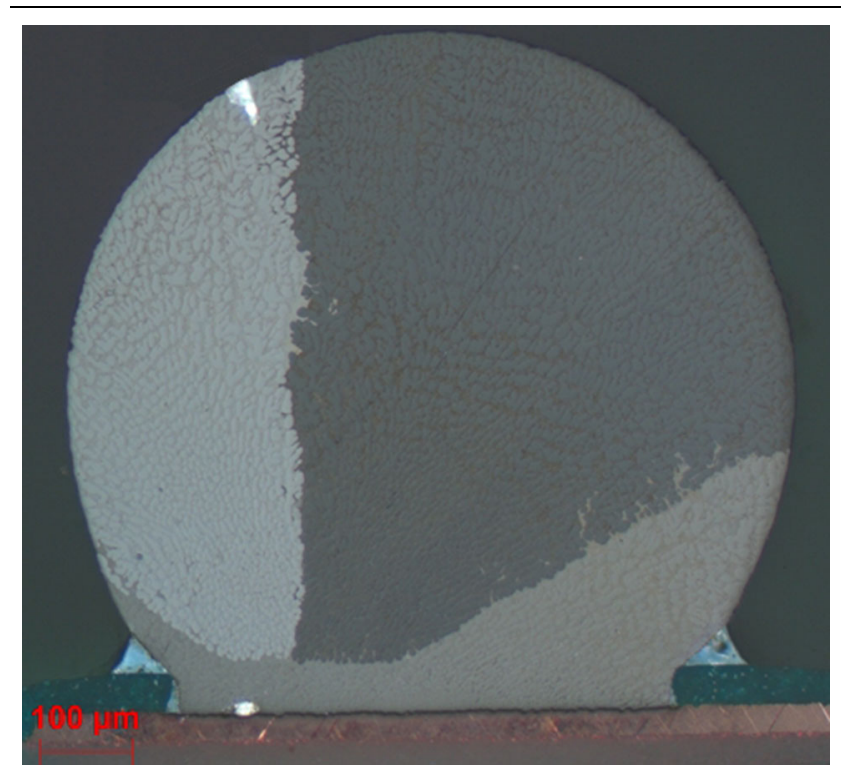

Fig. 1. Cross-polarizer microscopy image of an $\mathrm{Sn3Ag0.5Cu}$ solder joint with a typical 'beach ball structure'. 
results to life span in long-term service. At the present stage, this requires a number of approximations, each of which is discussed. The strong anisotropy of the Sn grain structure has, for example, major effects on the life of individual joints. ${ }^{22-24}$ There is no reason why these couldn't be incorporated into future versions of our mechanistic model, but for now, we shall focus on the average or 'typical' behavior, i.e., the prediction of $50 \%$ or $63.2 \%$ failure. As implicitly done in any other model until now, we shall treat effects of Sn grain orientation like statistical scatter.

Our discussion below relies on previously published results (as referenced), together with accelerated thermal cycling results now generated to complement these results, as well as results of a unique experiment that effectively deconstructs thermal cycling to allow for independent control of individual parameters.

\section{EXPERIMENTS}

The present effort involved conventional thermal cycling and an experiment combining loading in a micromechanical tester and thermal excursions. After cycling, solder joints were cross-sectioned and the microstructure characterized by cross-polarizer microscopy. Selected samples were further analyzed by electron backscatter diffraction (EBSD).

\section{Thermal Cycling}

The thermal cycling experiments employed sets of simplified (model) BGA assemblies designed to control specific parameters. Each package consisted of a $0.5-\mathrm{mm}$-thick silicon 'die' sandwiched between two identical 0.4-mm-thick FR4 substrates using thin layers of a rigid flip chip underfill to attach and extend up the edges to fully encapsulate the die. ${ }^{3}$ In each case, the die is almost as large as the substrates and thus covers a larger area than the solder pad array, so that all pads are located in the die region. This fully balanced construction led to an effective coefficient of thermal expansion (CTE) of $5.5 \mathrm{ppm} /{ }^{\circ} \mathrm{C}$, i.e., much lower than for commercial components. The corresponding large mismatch with the PCB was compensated for by keeping the distances to the neutral point (DNPs) in the designs low enough to limit the nominal shear strain ranges to one or a few percent in cycling. The components were attached to four-layer FR4-based PCBs. Soldering was conducted using a reflow profile with a peak temperature of $243^{\circ} \mathrm{C}$ and a total time of $40 \mathrm{~s}$ above $217^{\circ} \mathrm{C}$.

One set of components included three different designs. Each component had an 8 by 8 array of 0.38-mm-diameter solder mask-defined copper pads (Fig. 2) on a constant pitch of $1.0 \mathrm{~mm}, 1.4 \mathrm{~mm}$, or $1.8 \mathrm{~mm}$. SAC305 spheres with $0.508 \mathrm{~mm}$ diameters were reflowed onto the pads using a no-clean flux, and residues were removed with isopropyl alcohol
(IPA) afterwards. SAC305 type III no-clean solder paste was printed onto the pads through circular apertures with $0.38-\mathrm{mm}$ diameter, the same size as the solder mask openings, in a $0.125-\mathrm{mm}$-thick stencil before placement. These assemblies were tested in $0 / 100^{\circ} \mathrm{C}$ and $-40 / 125^{\circ} \mathrm{C}$ cycling with heating and cooling rates of $10^{\circ} \mathrm{C} / \mathrm{min}$. Dwell times were varied from $10 \mathrm{~min}$ to $120 \mathrm{~min}$ (same time at both temperature extremes).

Another set of components had 0.508-mm-diameter SAC305 solder spheres in a conventional 256 input/output (I/O) partially depleted area array with a $1.0-\mathrm{mm}$ pitch (Fig. 3). SAC305 type III noclean solder paste was printed onto the pads through circular apertures with $0.406-\mathrm{mm}$ diameter, the same size as the solder mask openings, in a 0.125-mm-thick stencil before placement. These assemblies were tested in $0 / 80^{\circ} \mathrm{C}, 0 / 100^{\circ} \mathrm{C}$ and $-40 / 125^{\circ} \mathrm{C}$ thermal cycling. In this case, the dwell time at low temperature was kept fixed at $15 \mathrm{~min}$, while two different high-temperature dwell times were considered, $15 \mathrm{~min}$ and $60 \mathrm{~min}$.

Yet another set of $256 \mathrm{I} / \mathrm{O}$ components (Fig. 3) had 3 different combinations of pitch, non-solder maskdefined (NSMD) pad size and solder ball diameter. These parameters were varied together to ensure that solder joint shapes remained the same and the nominal strain ranges in thermal cycling did too. One design had 0.41-mm-diameter solder balls on $0.3-\mathrm{mm}$-diameter pads a $0.8-\mathrm{mm}$ pitch. Another had $0.51-\mathrm{mm}$ balls on $0.41-\mathrm{mm}$ pads on a $1.0-\mathrm{mm}$ pitch. The last one had $0.76-\mathrm{mm}$ balls on $0.56-\mathrm{mm}$ pads on a $1.27-\mathrm{mm}$ pitch. The assemblies were cycled between $0^{\circ} \mathrm{C}$ and $100^{\circ} \mathrm{C}$ with dwells of either $15 \mathrm{~min}$ or $60 \mathrm{~min}$ at both extremes.

Finally, one such experiment employed one additional combination of pitch, pad size and solder ball diameter ensuring the same nominal strain ranges in thermal cycling: $0.3-\mathrm{mm}$ balls on $0.24-\mathrm{mm}$ pads on a $0.5-\mathrm{mm}$ pitch. In this case, the assemblies were cycled between $0^{\circ} \mathrm{C}$ and $100^{\circ} \mathrm{C}$ with dwells of $60 \mathrm{~min}$ at both extremes.

Components and PCBs were all daisy-chained to allow in situ monitoring with an Anatech 256 STD event detector which was programmed to poll samples every $2 \mathrm{~s}$ and record resistance increases surpassing 300 ohms for more than $200 \mathrm{~ns}$, in accordance with IPC-9701. Results were fitted by Weibull distributions to extract values for the characteristic life or scale parameter, $N_{63}$.

\section{'Deconstructed Thermal Cycling'}

A different experiment relied on a combination of isothermal loading and temperature variations. Both bumps on pads and full assemblies were tested.

Solder bumps on pads were prepared by reflow soldering 0.75 -mm-diameter spheres onto $0.55-\mathrm{mm}$ diameter $\mathrm{Cu}$ pads on typical BGA component substrates. Soldering was accomplished by first 


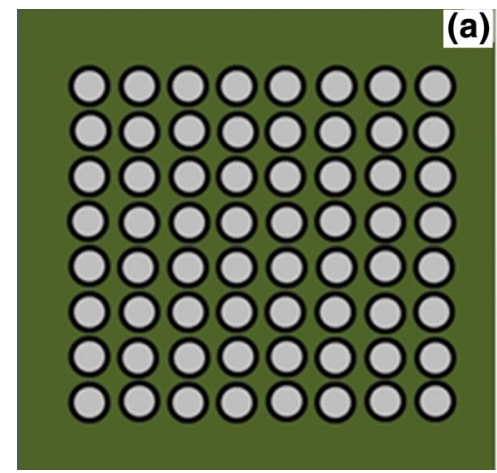

(a)

(b)

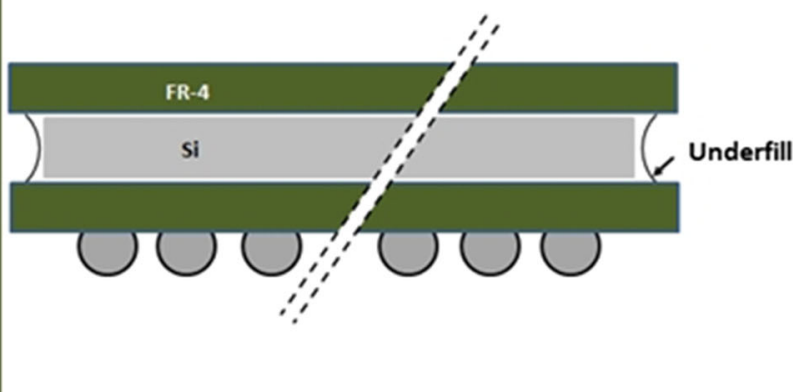

Fig. 2. Model component bottom (a) and side view (b).

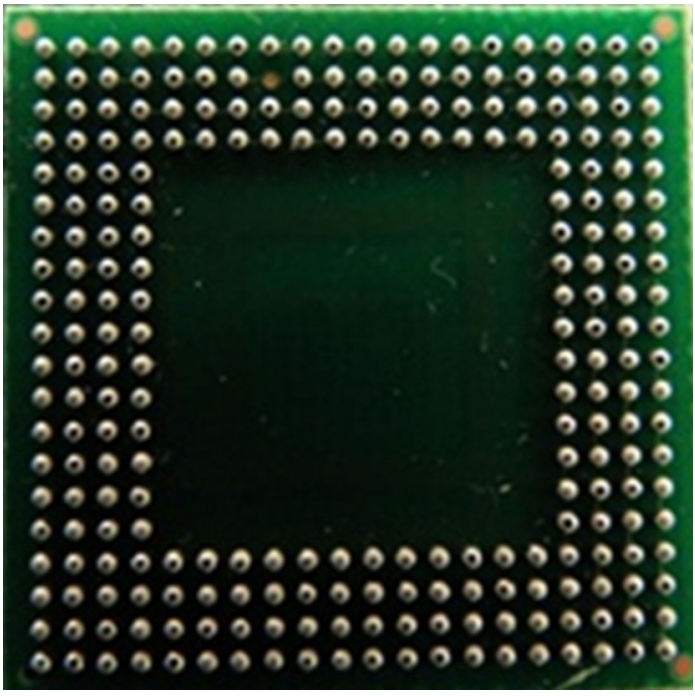

Fig. 3. Model component bottom view.

printing a tacky flux through a stencil onto the substrate pads and then placing individual spheres through apertures in a separate 'bumping' stencil. Reflow was done as above.

A row of 18 joints was first annealed for $48 \mathrm{~h}$ at $100^{\circ} \mathrm{C}$ in order to coarsen and stabilize the secondary precipitates, then loaded simultaneously in shear in an Instron tensile tester (Fig. 4). Individual joints were loaded to the designated creep load at a rate of approximately $0.3 \mathrm{MPa} / \mathrm{s}$ after which the load was maintained for $5 \mathrm{~min}$. In one version of the experiment, the loading was then reversed to bring the joints back to the original position over a period of about $5 \mathrm{~min}$, and this was followed by a 1-h anneal at $100^{\circ} \mathrm{C}$. In another version of this experiment, the joints were heated to $100^{\circ} \mathrm{C}$ and the loading reversed during the 1-h anneal. In either case, the loading-annealing sequence was repeated multiple times (cycles).

The assemblies tested were designed to have no CTE mismatch. For this purpose, 0.75-mm-diameter SAC305 solder spheres were soldered between 0.4-mm-thick FR4 substrates with 0.55-mm-diameter

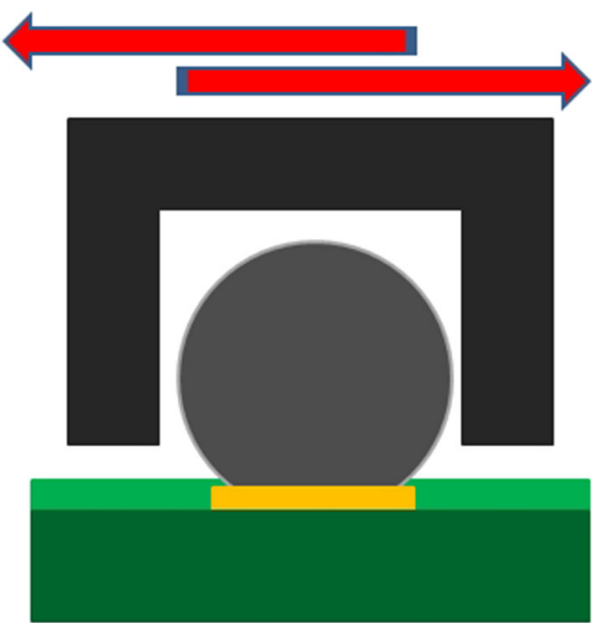

Fig. 4. Sketch of shear loading of solder bump.

copper pads. The substrates were similar to those used to make the model components above, but no silicon chip was attached to any of them. Attachment was done as above using a tacky flux.

These assemblies were annealed for $72 \mathrm{~h}$ at $125^{\circ} \mathrm{C}$ to coarsen and stabilize the secondary precipitates. The assemblies were then cut to sections containing a total of 16 joints in order to stay within the load limit of the load cell on the Instron micro-mechanical tester. The top and bottom substrates were glued to the Instron fixtures and the assemblies cycled in shear.

The use of assemblies meant that the tester was in contact with the samples during all stages of a cycle. In this case, samples were sheared at a rate of $1 \mu \mathrm{m} / \mathrm{s}$ to a selected maximum load at room temperature. At that point, the displacement was fixed and maintained for $5 \mathrm{~min}$, during which he load dropped. The load was then returned to zero, after which the temperature was raised to $100^{\circ} \mathrm{C}$. Both substrates were heated, keeping temperature differences at a minimum so that, in the absence of a CTE mismatch, there were no stresses on the joints. The thermal expansion of the fixtures and machine were automatically compensated for by adjusting 
the displacement to maintain a negligible mechanical load during heating. Once the temperature was stabilized at $100^{\circ} \mathrm{C}$, the assembly was sheared in the opposite direction to an extension calculated, taking creep into account, to ensure symmetry of the entire cycle. This extension was then maintained for $15 \mathrm{~min}$ at $100^{\circ} \mathrm{C}$, allowing for significant load relaxation. The load was finally reduced to zero and the assembly then cooled to room temperature while again maintaining a negligible mechanical load. Figure 5 shows the entire load history in a cycle.

This is clearly not an exact replication of the temperature, stress and strain versus time profiles experienced by solder joints in a real assembly in thermal cycling. Not only are the joints not loaded during heating and cooling, joints in a real assembly will undergo a combination of continuous load relaxation and creep during the dwells. However, the important features are well-represented.

The Instron offers displacement control through the use of a preloaded ballscrew drive system equipped with both a rotary encoder and a $20-\mathrm{nm}$ resolution linear glass-scale encoder. Displacements by the linear encoder do, of course, include load cell, and load frame deflections, as well as test specimen deflection. The electromechanical (non-hydraulic) drive system has a stiffness (without specimen) between $600 \mathrm{gf} / \mu \mathrm{m}$ and $2000 \mathrm{gf} / \mu \mathrm{m}$, depending on the cross-head position. The fixturing does, however, lead to a reduction in this. The overall machine stiffness was measured to exceed that of our solder joints by a factor of about 3 . This is by no means negligible, but we have chosen not to correct for this. The values for work per cycle should not depend on the machine stiffness and are believed to be accurate.

\section{Microstructure Analysis}

Assemblies were mounted in epoxy and crosssectioned, then ground on silicon carbide polishing paper with grid sizes 240-4000, followed by finer polishing with $3-\mu \mathrm{m}, 1-\mu \mathrm{m}$ and $0.5-\mu \mathrm{m}$-diamond suspensions. After each step, the samples were

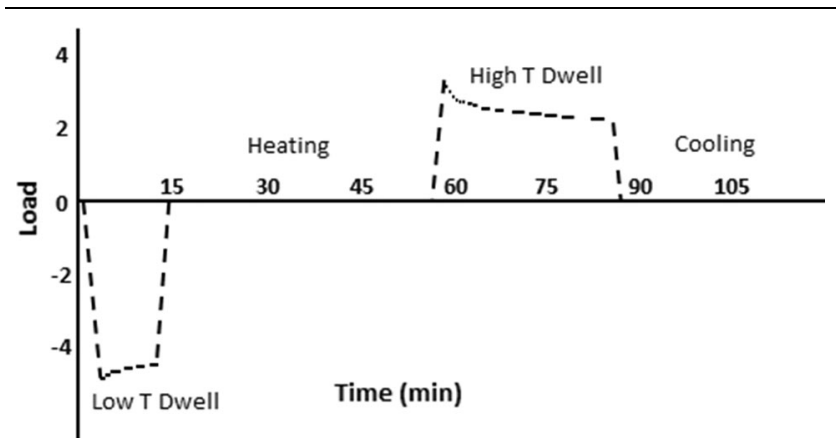

Fig. 5. Load versus time in a single cycle of de-constructed thermal cycling of assemblies. rinsed in water and gently cleaned with a cotton applicator. Final polishing was performed with an $0.02-\mu \mathrm{m}$ colloidal silica solution.

Cross-sections were inspected for grain structure by cross-polarizer microscopy and EBSD.

\section{MECHANISMS}

Our model, first of all, relies on the evolution of damage and failure of typical $\mathrm{SnAgCu}$ solder joints in thermal cycling being governed by a 'continuous' recrystallization process. Like others, we have previously referred to this as dynamic recrystallization, but work is now being undertaken to specifically address whether the actual process is in fact 'dynamic', rather than akin to multiple alternations between cold working and annealing. This has significant consequences for the formulation of a quantitative model. Based on previously published work, we first argue for the recrystallization being continuous and dynamic, but sensitive to the spacing (coarsening) of the secondary $\mathrm{Ag}_{3} \mathrm{Sn}$ precipitates. Direct experimental evidence of the predominantly dynamic nature is presented in the next section, allowing for the formulation of a quantitative damage function.

\section{Damage and Failure}

It has long been recognized that the failure of area array solder joints of $\mathrm{SnAgCu}$ in accelerated thermal cycling involves recrystallization within the Sn grains. ${ }^{5-10}$ A modification of the conventional dye-and-pry technique allowed the measurement of very small fatigue cracks and, contrary to popular belief, the crack initiation stage was found to be negligible in thermal cycling. ${ }^{11}$ Crack growth did, however, remain quite limited until a continuous network of high-angle grain boundaries had been established across the high-strain region in the joint. ${ }^{11,13}$ At that point, fatigue cracks started to propagate much more rapidly through the region (Fig. 6).

Yin et al. ${ }^{12}$ conducted a set of thermal cycling tests on model BGA assemblies with 0.5-mm-diameter SAC305 solder balls between $\mathrm{Ni} / \mathrm{Au}$ pads on the components and $\mathrm{Cu}$ pads on the PCB. Systematic variations in strain rates and ranges, cycling temperatures and dwell times led to differences of up to an order of magnitude in the number of cycles before electrical failure, but the number of cycles to completion of the recrystallized band across a corner joint was always roughly $1 / 3$ of the total life span. ${ }^{12}$ It is, of course, highly unlikely that crack propagation during the remaining $2 / 3$ of the life span would vary in the same, non-trivial way with strain range, dwell times, and temperatures as recrystallization unless the mechanisms are closely linked. Bieler and co-workers suggested that crack evolution is controlled by the ongoing rotation of subgrains until they reach a particular orientation. ${ }^{23,25}$ More work is needed to fully understand the actual mechanism, 

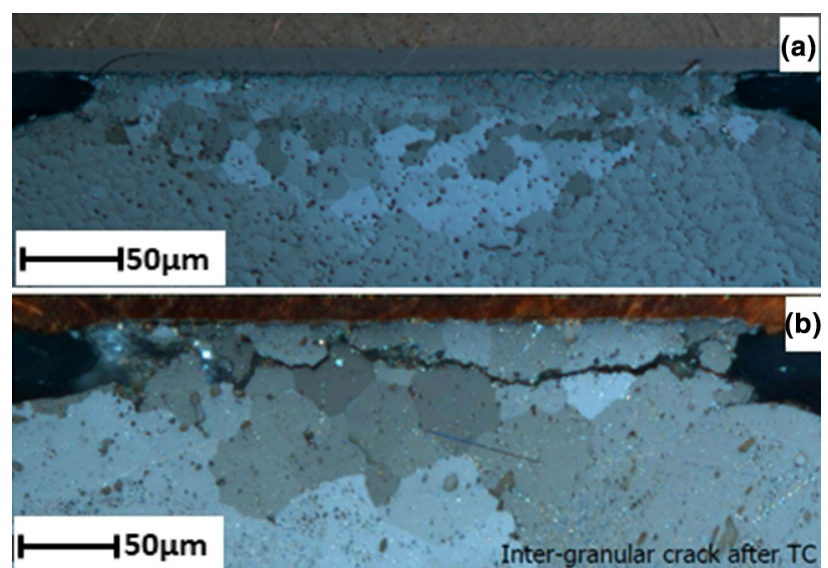

Fig. 6. Effects of thermal cycling. (a) Recrystallized region with a small crack in the SnAgCu solder joint; and (b) fatigue crack through the recrystallized region.

but that is not important for our model at the present stage.

What is of practical consequence is the empirical indication that we can predict the time to failure of a particular set of solder joints if we can predict the rate of recrystallization. At an extreme of very small strain ranges, short dwell time at high temperature, and low maximum temperature, crack growth may conceivably proceed without extensive recrystallization. However, thin-chip BGAs (CTBGAs) and chip array BGAs (CABGAs) survived 10,000 cycles (24 months) or more in $20 / 80^{\circ} \mathrm{C}$ with 30 -min dwells and still failed by recrystallization followed by crack growth along the high-angle grain boundaries. ${ }^{21} \mathrm{We}$ therefore base our model on the assumption of a correlation with recrystallization.

As we shall see below, the life span is in fact often less than 3 times the number of cycles required to complete the network of grain boundaries across the joint. This is because recrystallization at lower strain ranges, including at those typical of longterm service, tends to be delayed until the secondary precipitates have coarsened somewhat. This complicates the prediction of life span in long-term service.

\section{Recrystallization}

Our model relies on the recrystallization being a so-called 'continuous' process, i.e., one that does not involve a nucleation step. By far, the most common recrystallization processes are those that involve both a nucleation and a growth step. However, nucleation of a new grain is only stable if the misorientations are large enough, so high-angle grain boundaries must occur abruptly. ${ }^{26}$ In contrast, continuous recrystallization is a recoverydominated process leading to ongoing increases in boundary misorientation and conversion of lowangle boundaries into high-angle ones by coalescence and rotation.
The stacking fault energy does not appear to have been measured for the $\mathrm{SnAgCu}$ solder alloys, but it has been argued that it must be high. ${ }^{27}$ This would tend to favor continuous, rather than discontinuous, recrystallization. ${ }^{26}$ Also, the misorientation of the $\mathrm{Ag}_{3} \mathrm{Sn}$ precipitates is by nature high. Indeed, detailed studies have shown thermal cycling of $\mathrm{SnAgCu}$ joints to first lead to the formation of new subgrains within the individual $\beta$-Sn dendrites ${ }^{12}$ ), and eventually between the densely spaced precipitates as well, after which these subgrains then continue to rotate during ongoing cycling. ${ }^{8,12,23,25} \mathrm{In}$ fact, while the extent of the recrystallized region does not seem to change much beyond the stage shown in Fig. 6, the subgrains continue to rotate towards ever greater degrees of misorientation. ${ }^{12,23}$ Aside from the fact that new grains first observed after a limited number of cycles all had small misorientations ${ }^{12,23}$ and that larger angles tended to evolve gradually, we shall see below that further systematics support the assumption of a continuous recrystallization process as well.

Furthermore, important for our model is whether the major part of the recrystallization process is in fact dynamic. Dynamic recrystallization occurs simultaneously with the creation of dislocations; by an ongoing coalescence and rotation of the dislocation cells, the recovery is accelerated by the excess vacancies. ${ }^{26}$ However, this excess tends to disappear within seconds after the loading stops. ${ }^{26}$ It is actually not easy to cause extensive recrystallization within a typical $\mathrm{SnAgCu}$ solder joint. Sn has a very large number of different slip systems so it is not surprising ${ }^{28}$ that it tends to form three-dimensional dislocation cell structures during inelastic deformation. ${ }^{27,29}$ However, systematic isothermal cycling experiments led at most to very limited, local recrystallization near the crack tip. ${ }^{24,30-34}$ In fact, Korhonen et al. ${ }^{34}$ conducted isothermal cycling experiments on single-crystal $\mathrm{Sn} 3.8 \mathrm{Ag} 0.7 \mathrm{Cu}$ samples at different temperatures ranging from $-25^{\circ} \mathrm{C}$ to $125^{\circ} \mathrm{C}$, reproducing the strains and dwell times common in thermal cycling, without creating significant recrystallization. Recrystallization occurred more readily in solder joints with lower Ag concentrations, and thus greater average spacing between the $\mathrm{Ag}_{3} \mathrm{Sn}$ precipitates. ${ }^{24,30,31}$ Pre-annealing $\mathrm{Sn} 3 \mathrm{Ag} 0.5 \mathrm{Cu}$ joints to coarsen the precipitates before cycling allowed for more recrystallization as well. ${ }^{30,33}$ Nevertheless, none of the experiments came close to reproducing the extent of recrystallization common in thermal cycling.

We suggest that a relatively low temperature is required for the establishment of a reasonably stable dislocation cell structure, while a higher temperature is needed for the cells to coalesce and rotate. We found cycling between $25^{\circ} \mathrm{C}$ and $100^{\circ} \mathrm{C}$, and between $-40^{\circ} \mathrm{C}$ and $60^{\circ} \mathrm{C}$, as well as between $20^{\circ} \mathrm{C}$ and $80^{\circ} \mathrm{C}$ to all lead to the usual level of recrystallization of $\mathrm{Sn} 3 \mathrm{Ag} 0.5 \mathrm{Cu}$ joints before failure, ${ }^{35,36}$ suggesting that a low temperature of $25^{\circ} \mathrm{C}$ 
is low enough to stabilize the initial structure while a high temperature of $60^{\circ} \mathrm{C}$ is high enough to allow for coalescence and rotation. However, repeated temperature variations (cycling) are definitely needed.

Indeed, following isothermal cycling at room temperature with annealing at an elevated temperature such as $100^{\circ} \mathrm{C}$ led to more recrystallization. Alternating instead between isothermal cycling and annealing up to three times, ending up with the same total number of cycles and total annealing time, was found to enhance the recrystallization significantly. ${ }^{30}$ The effect did, however, still remain very limited, ${ }^{30}$ and it was questioned whether the much more extensive recrystallization in thermal cycling can simply be ascribed to the larger number of temperature excursions.

There is no doubt that a 'steady-state' dislocation cell structure is established during the low-temperature dwell. Our 'deconstructed thermal cycling' experiment showed the stress in each low-temperature dwell to drop quickly during the first few minutes after which the strain rate became almost constant. $^{37}$ That measurement was conducted at room temperature, and the establishment of a nearsteady-state dislocation cell structure may take a little longer during a lower-temperature dwell, but the structure is still expected to become almost constant after less than $10 \mathrm{~min}$ at $0^{\circ} \mathrm{C}$. Indeed, an increase in low-temperature dwell time from $0.5 \mathrm{~min}$ to $15 \mathrm{~min}$ led to a significant reduction in solder joint life span, while extensions beyond that had little or no effect. ${ }^{1}$

The absence of significant recrystallization in isothermal cycling at a temperature like $100^{\circ} \mathrm{C}$ or $125^{\circ} \mathrm{C}^{34}$ suggests that dislocations created there are annihilated too quickly, or that a sufficiently dense cell structure on which dislocations can continue to multiply is never established. However, we suggest that a pre-existing dislocation structure established during the low-temperature dwell can help multiply and stabilize the high-temperature dislocations long enough for them to coalesce and rotate as well. If so, this might be the reason that thermal cycling leads to so much more recrystallization.

The formulation of an actual damage function will require us to first resolve whether the recrystallization is dominated by the dislocations generated at low or high temperature, i.e., whether the dominant recrystallization process is dynamic or not.

\section{Effects of Precipitates}

Recrystallization may be inhibited by Zener pinning of subgrain boundaries at precipitates. ${ }^{38}$ In the case of thermal cycling of the $\mathrm{SnAgCu}$ alloys, this is dominated by the secondary $\mathrm{Ag}_{3} \mathrm{Sn}$ precipitates. As we shall argue below, initial precipitate spacings in SAC305 tend to be small enough to prevent the coalescence and rotation of the dislocation cells unless the strain ranges, and thus the stresses, are quite high. This means that a relatively high dislocation density is rapidly established, but nothing further happens until cycling-induced precipitate coarsening ${ }^{39}$ leads to a sufficiently large spacing.

\section{DAMAGE FUNCTION}

Based on the above, we seek a comprehensive damage function to predict the rate of recrystallization based on the generation of dislocations during both the low- and high-temperature dwells together with the coalescence of the resulting cells during the latter. This can be viewed as a combination of a (semi-) static and a dynamic recrystallization process. As we shall see, this is complicated by effects of precipitate spacing and thus coarsening.

Discontinuous dynamic recrystallization has been modeled based on the fraction of the overall deformation energy (work) stored in dislocations. ${ }^{40-44}$ However, the steady-state dislocation structure generated during the low-temperature dwell remains stable after a few minutes ${ }^{37}$ even though the work there continues to increase. Anyway, as we shall see, it appears that the contribution of the low temperature to the overall rate of recrystallization is in fact minor. As for the dynamic part of the present continuous process, we suggest that contribution may scale with the amount of work done during the high-temperature dwell.

\section{Dominant Recrystallization Process}

Comparing the life span in $-20 / 100^{\circ} \mathrm{C}$ cycling to that of the same assemblies in $0 / 100^{\circ} \mathrm{C}$ cycling for 5 different CSP assembly designs, the effect of lowering the minimum temperature by $20^{\circ} \mathrm{C}$ was found to be very weak, on the order of $10 \%$ or less. ${ }^{37} \mathrm{We}$ would expect the steady-state dislocation density to be considerably higher at the lower temperature, so this does not seem to support a major effect of that density. Indeed, a 'deconstructed thermal cycling' experiment conducted on rows of SAC305 joints as described above shows much stronger effects of dislocations generated during the high-temperature dwell.

Figures 7, 8 and 9 show EBSD images of typical SAC305 joints after 100, 115, and 130 'deconstructed thermal cycles'. In this case, each 'cycle' first maintained an average shear stress of $8 \mathrm{MPa}$ on the joints for $5 \mathrm{~min}$, after which the loading was then reversed to bring the joints back to the original position over another period of about 5 min. This was all done at room temperature and followed by a 1 -h anneal at $100^{\circ} \mathrm{C}$. The joint-to-joint variation is significant, but, overall, it is clear that without contributions from dislocations generated at the high temperature simultaneously with the coalescence and rotation, the recrystallization is significant but limited.

Figure 10 shows similar images of 7 joints after 94 cycles except that in each of these the reversed 

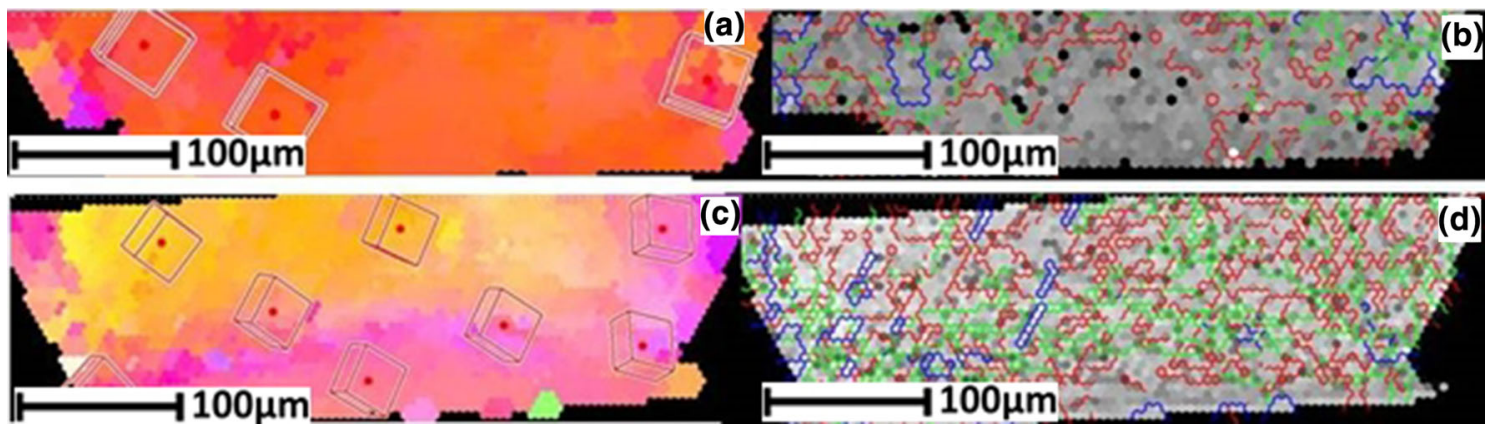

Fig. 7. EBSD images of the high-strain regions in two SAC305 joints after 100 cycles with no dynamic recrystallization contribution. (a and c) Color maps showing different Sn orientations in two different joints; (b and d) lines indicating boundary misorientations (red 2-5 ${ }^{\circ}$, green $5-10^{\circ}$, blue $>10^{\circ}$ ) in the same joints (Color figure online).

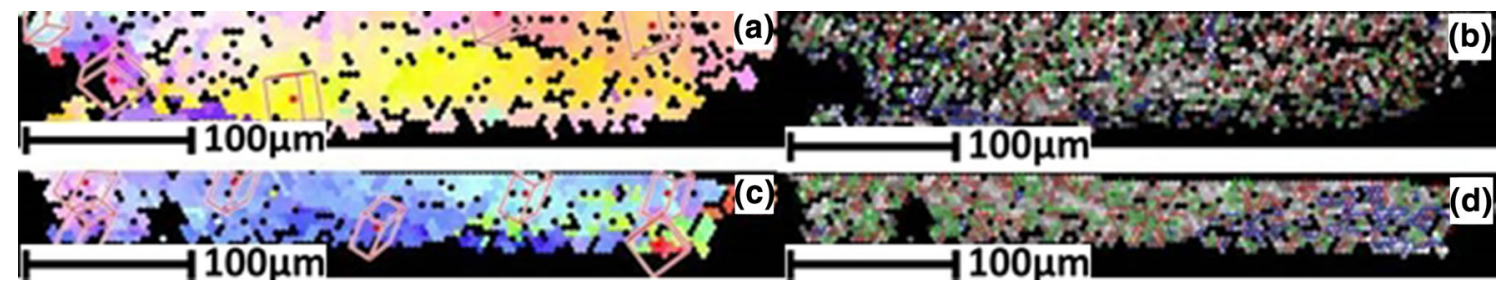

Fig. 8. Like Fig. 7, but two other joints after 115 cycles. (a and c) Color maps showing different Sn orientations; (b and d) lines indicating boundary misorientations (red $2-5^{\circ}$, green $5-10^{\circ}$, blue $>10^{\circ}$ ) (Color figure online).

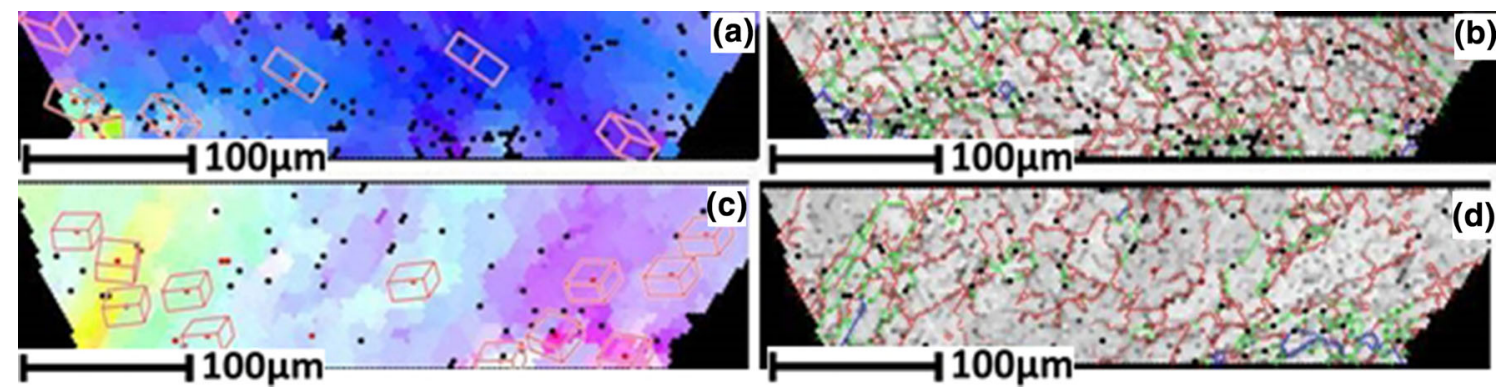

Fig. 9. Like Fig. 7, but two other joints after 130 cycles. (a and c) Color maps showing different Sn orientations; (b and d) lines indicating boundary misorientations (red $2-5^{\circ}$, green $5-10^{\circ}$, blue $>10^{\circ}$ ) (Color figure online).

load was applied at $100^{\circ} \mathrm{C}$ instead. The degree of recrystallization is again seen to vary quite strongly from joint to joint, something which can be ascribed to the different $\mathrm{Sn}$ grain orientations. Bieler et al. ${ }^{22,23}$ have shown the rate of damage in thermal cycling to vary strongly with orientation, and a forthcoming publication will show how the rate of recrystallization varies with the loading direction relative to the orientations and number of multiple slip planes in the Sn. Anyway, overall, it is clear that the additional contributions of dislocations generated during the high-temperature dwell provide for much more recrystallization, i.e., the dominant process is dynamic.

We argue below (constitutive relations) that the inelastic work during the high-temperature dwell is dominated by diffusion along the cycling-induced dislocation structures and thus offers a relative measure of the density of these. This leads us to suggest that the rate of recrystallization may scale with the high-temperature work per cycle for a given value of that temperature. Indeed, preliminary results appear to support this.

\section{Scaling with Work}

In this experiment, the special assemblies, designed to have no CTE mismatch between substrate and 'component', were first annealed for $72 \mathrm{~h}$ at $125^{\circ} \mathrm{C}$ to coarsen and stabilize the secondary precipitates. The assemblies were then subjected to two different 'deconstructed thermal cycling' experiments. In each case, they were sheared at room temperature, followed by a 5 -min dwell there, and then sheared in the opposite direction at $100^{\circ} \mathrm{C}$, followed by a dwell there.

Figure 11 shows the inelastic work done during each high-temperature dwell versus cycle number 

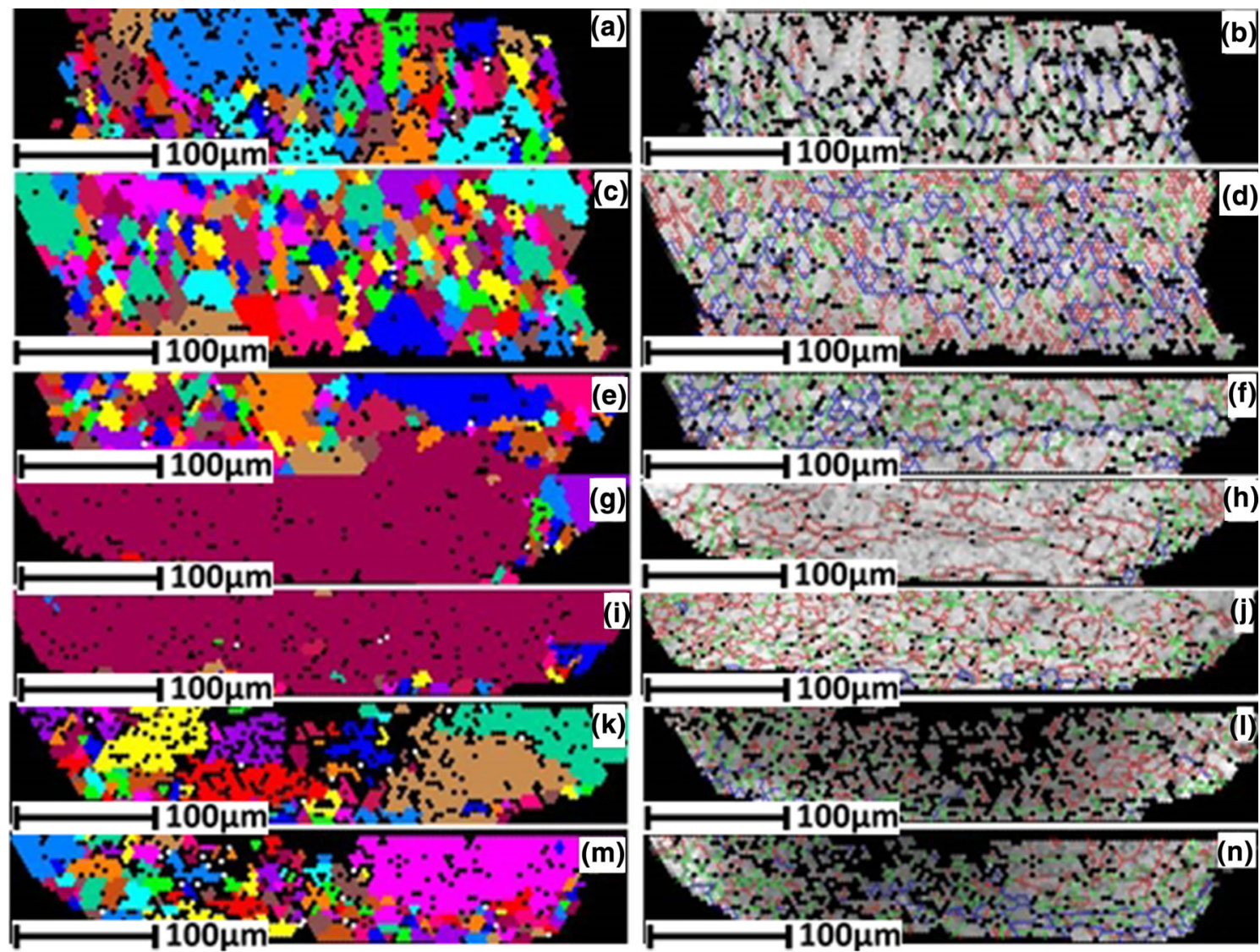

Fig. 10. EBSD images of the high-strain regions in 7 SAC305 joints after 94 cycles including dynamic recrystallization contribution. (a, c, e, g, i, $k$, and $\mathrm{m}$ ) Color maps showing different $\mathrm{Sn}$ orientations in the seven joints; (b, d, f, h, j, l, and $\mathrm{n}$ ) lines indicating boundary misorientations (red 2-5 green $5-10^{\circ}$, blue $>10^{\circ}$ ) in the same joints (Color figure online).

for two different strain ranges. The upper curve corresponds to an experiment where the low-temperature dwell started out with a nominal shear stress of $12 \mathrm{MPa}$, while the lower curve corresponds to an initial stress of $10 \mathrm{MPa}$ in each cycle. The lowtemperature strain ranges differed accordingly and, notably, so did the high-temperature strain ranges. Cycling was terminated when the stiffness dropped rapidly, indicating the failure of most of the joints. The high-temperature work per cycle varied by about a factor of 2 as did the number of cycles to failure, 34 and 60 , respectively. The total work to failure differed by less than $1 \%$. Only one assembly was tested in each case. However, unlike in conventional thermal cycling, where failure is defined by the first joint to fail and only (near-) corner joints are subject to the maximum stress/strain amplitude, our 'deconstructed thermal cycling' experiment subjects all the 16 joints in an assembly to the same conditions. To some extent, the results can thus be viewed as reflecting averages over 8-16 joints each. Cross-polarizer microscopy confirmed extensive recrystallization in spite of the low number of cycles.

For now, we thus propose a scaling of the amount of recrystallization with the amount of work done

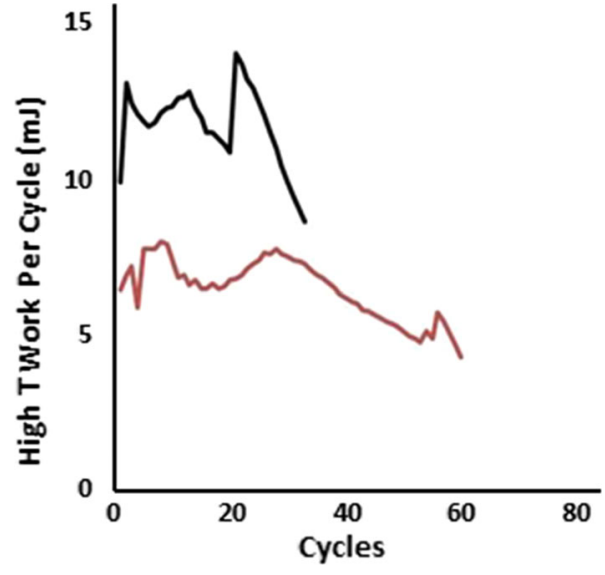

Fig. 11. Inelastic work during the $100^{\circ} \mathrm{C}$ dwell of each cycle until failure in 'deconstructed thermal cycling' experiment with initial nominal shear stresses of $12 \mathrm{MPa}$ (top) and $10 \mathrm{MPa}$ (bottom) at room temperature.

during the high-temperature dwell. We are free to do that because we do not actually associate a measurable microstructural quantity with 'recrystallization per cycle'. All that we rely on is a definition of $100 \%$ recrystallization. We take this 
to denote the completion of a continuous network of grain boundaries across the high-strain region. As discussed above, this and the subsequent crack growth to failure can be viewed as a single process which takes three times as many cycles, $N_{\text {recr. }}$ The inverse of this, $1 / N_{\text {recr, }}$, is then proportional to the average value of the inelastic work done during the high-temperature dwell, $\Delta W$.

\section{Precipitate Coarsening}

In the above experiment, assemblies were first annealed for $72 \mathrm{~h}$ at $125^{\circ} \mathrm{C}$ to coarsen and stabilize the secondary precipitates. This may be the reason why the onset of recrystallization was not delayed by Zener pinning of dislocation cells at the $\mathrm{Ag}_{3} \mathrm{Sn}$ precipitates. Also, the strain ranges were unusually high, as evidenced by the very short life span. In general, the 'pinning pressure' increases with precipitate size and decreases with the average spacing, making it proportional to the volume fraction $F_{\text {prec }}$ divided by the average size $d_{p}{ }^{26}$ Indeed, as mentioned above, recrystallization occurs more readily in solder joints with lower Ag concentrations and/or after pre-annealing to coarsen the precipitates. $^{24,30,31,33}$ In the absence of pre-annealing and/ or for lower strain ranges, in particular, those typical of long-term service conditions, quantitative predictions will require pinning to be accounted for.

Below we shall propose, as an initial approximation, that the coalescence and rotation of dislocation cell structures can be assumed to continue during the high-temperature dwell as long as the stress is high enough to ensure a driving pressure that is higher than the Zener pinning pressure. ${ }^{45}$ The stress keeps dropping with time during a given dwell (below), but the pinning pressure drops (with $F_{\text {prec }} / d_{p}$ ) from cycle to cycle as the precipitates coarsen. For sufficiently low-strain ranges and initial precipitate sizes, the rate of recrystallization remains strongly reduced until after significant coarsening. ${ }^{12,13,30,33}$ Since the initial precipitate size is sensitive to the degree of undercooling after reflow, this leads to systematic effects of solder joint dimensions and pad finishes on acceleration factors. ${ }^{46}$

Clearly, failure to account for effects of precipitate coarsening on the damage function would lead to conservative extrapolations of test results to life span in milder cycling. As for the actual life span in long-term service, the resulting error may be counteracted somewhat by the much longer times available for coarsening there.

\section{Constitutive Relations}

Before turning to the formulation of a practical approximation for a damage function, we need to face another complication. In short, as demonstrated in a recent conference paper, constitutive relations currently used in modeling may be seriously misleading. ${ }^{4}$
Keeping all other parameters constant, the life span of an area array assembly in thermal cycling tends to scale with the inverse of the DNP of the most stressed joints, typically but not always the corner joints, to a power of 2 or more,,$^{2,3}$ a trend also found for our BGA assemblies below (Fig. 16). Assuming common constitutive relations, FEM of representative assemblies did, however, show the work done during the high-temperature dwell (only) to vary as $\mathrm{DNP}^{0.6 .3}$. This is a result of the strong dependence assumed for the inelastic strain rate on the stress. Current constitutive relations for solder typically predict inelastic rates of deformation that vary with the stress to a power of 6 or more. ${ }^{4-55}$ However, simple calculations ("Appendix") show how this cannot lead to work during the hightemperature dwell that varies faster than the DNP. Only a linear dependence of the inelastic strain rate on the stress is compatible with a variation of the life span with $\mathrm{DNP}^{-2}$. As discussed in detail below, such a dependence is also consistent with observed dependencies on dwell times, and separate measurements of load relaxation during the high-temperature dwell of a 'de-constructed thermal cycling' experiment pointed to the same. ${ }^{47}$

A linear relationship between the stress and the steady-state creep rate suggests the dominance of the diffusion of individual vacancies rather than dislocation creep as commonly assumed, and forthcoming publications present systematic evidence to support the assumption that such diffusion is enhanced by cycling-induced dislocation structures. We suggest that, for a given high temperature and dwell time, the work during that dwell offers a relative measure of the density of these. This would be of relevance for a complete mechanistic understanding, but it has no consequences for our model at the present stage.

\section{General Damage Function}

As discussed above, Yin et al. ${ }^{12}$ reported a proportionality between the total number of cycles to failure, $N_{63}$, and the number of cycles required to complete a continuous network of high-angle boundaries across the high-strain region. This ratio remained constant across an order of magnitude variation in $N_{63}$, and thus presumably a significant variation in stresses, suggesting that a delay due to Zener pinning on the precipitates was not a significant factor in this case. However, pinning did appear to be significant for smaller joints in milder cycling. In fact, variations in acceleration factors with joint dimensions ${ }^{1,46}$ were consistent with the assumption of a threshold precipitate size, $d_{\mathrm{thr}}$, which decreases with increasing strain range. ${ }^{46}$

This assumption is, at best, a major simplification. Even a low-strain range may lead to a high enough stress for the resulting driving pressure for recrystallization to overcome the Zener pinning at the very beginning of the high-temperature dwell. 
On the other hand, a long enough dwell time will eventually lead to a stress that is too low to continue doing that. For intermediate values of strain range and initial precipitate size, the contribution of the first cycles to the overall recrystallization may, therefore, be limited to early parts of the dwell, whereas the contributions of subsequent cycles increase as the precipitates coarsen. As an approximation, once the precipitates reach a size where the stress remains large enough for the driving pressure to overcome the pinning during most of the dwell, we define that size as the threshold size associated with the strain range, and thus with the stress, $\sigma_{o}$, at the beginning of the dwell, i.e., $d_{\mathrm{thr}}\left(\sigma_{o}\right)$.

This then leads to an approximation for the characteristic life span at any strain range/rate

$$
N_{63}=N_{\text {ini }}+N_{\text {recr }}
$$

where $N_{\text {ini }}$ is the number of cycles for the precipitate spacing to grow from $d_{o}$ to $d_{\mathrm{thr}}\left(\sigma_{o}\right)$. This term is negligible in highly accelerated testing, but dominant under long-term service conditions, complicating quantitative extrapolations.

\section{PRACTICAL APPROXIMATIONS}

At the present stage, the formulation of a practical damage function will require further simplifying assumptions. It would be the hope that future research will lead to improvements on some of these, but the first set of assumptions are expected to stand for a while. We base our damage function on the approximation in Eq. 1.

\section{Recrystallization}

As discussed above, we take $1 / N_{\text {recr }}$ to be proportional to the average value, per cycle, of the inelastic work done during the high-temperature dwell, $\Delta W$. Of course, the number of cycles required to complete recrystallization and crack growth must also depend on the cross-section of the joint in the high-strain region. Figure 12 shows the life span of SAC305 joints in $0 / 100^{\circ} \mathrm{C}$ thermal cycling with 15 min and 60-min dwells versus the diameter of the solder mask-defined pads on the component. In this case, differently sized solder balls were mounted on corresponding contact pads with a pitch scaled so that the shear strain ranges on them were the same in a given cycle. It follows that the high-temperature work was roughly the same as well. The life span is seen to vary linearly with the pad diameter and thus with the cross-section, $L$, of the joint in the high-strain region near it.

For a given temperature and dwell, $\Delta W$ is, as argued above, assumed to be proportional to the density of the dislocation structures, but the rate of recrystallization must also vary with the rate of coalescence and rotation of the cells, i.e., it must increase with temperature for a given $\Delta W$. We thus propose an expression

$$
N_{\text {recr }}=\Phi_{o} * L /\left\{\Delta W * f\left(T_{\max }\right)\right\}
$$

where $\Phi_{o}$ is a constant and $f\left(T_{\max }\right)$ is approximated by an Arrhenius function. Even though $\Delta \mathrm{W}^{-1}$ increases with temperature, with an activation energy equal to that of diffusion ("Appendix"), experiments invariably show $N_{\text {recr }}$ to decrease, so the effective activation energy in $f\left(T_{\max }\right)$ must be significantly higher.

In the absence of quantitative constitutive relations that account properly for the apparent dominance of diffusion creep in thermal cycling, further approximations are required. As outlined in the "Appendix", the assumption of steady-state diffusion creep alone leads to a $\Delta W_{\mathrm{ss}}$ that starts out varying linearly with the dwell time $\left(\Delta W_{\mathrm{ss}}=\dot{W}_{\mathrm{ss}} \cdot t_{d}\right)$, but, in reality, the rapid reduction of the nominal strain rate to zero at the beginning of the high-temperature dwell must provide for a transient creep stage during which the inelastic strain rate is higher than predicted by the steady-state expression (Eq. 12). For now, we therefore express the total work in the dwell as the sum of a contribution from the transient creep during the first few minutes and a separate contribution from near-steady-state creep. This means that the rate of recrystallization per cycle can be approximated as proportional to $\left(\Delta W_{\mathrm{tr}}+\dot{W}_{\mathrm{ss}} \cdot t_{d}\right)$, where $\Delta W_{\text {tr }}$ accounts for the 'excess' work done during the first minutes. A scaling of the average damage rate with an expression like this, i.e.,

$$
1 / N_{63}=\beta+\alpha * t_{d}
$$

was shown to be in excellent agreement with the observed dwell time dependence for 4 different $\mathrm{SnAgCu}$ based alloys in $0 / 100^{\circ} \mathrm{C}$ cycling. ${ }^{2}$ Figure 13 shows the same for the present full-area array (Fig. 2) 95.5Sn3Ag0.5Cu-based BGA assemblies with three different distances to the neutral point (DNP), and thus three different strain ranges, on the corner joints.

Table I lists the parameters $\alpha$ and $\beta$ extracted from the fits to Eq. 3 in these figures. Both, of course, increase significantly with the DNP, but their ratio $\beta / \alpha=\xi$ (also included in the table) does not. The ratio $\Delta W_{\text {tr }} / \dot{W}_{\text {ss }}$ can thus be approximated as independent of the DNP and we can express the average damage rate function as

$$
1 / N_{63}=\alpha *\left\{\xi+t_{d}\right\}
$$

It follows from Eq. 22 ("Appendix") that this approximation must start to break down at sufficiently high values of the dwell time, $t_{d}$, the effective stiffness, $E_{\text {eff }}$, and/or the creep factor $K(T)$. Indeed, Fig. 14 shows results for the same assemblies in $-40 / 125^{\circ} \mathrm{C}$ cycling where $K(T)$ is significantly larger. Fits through the data points 

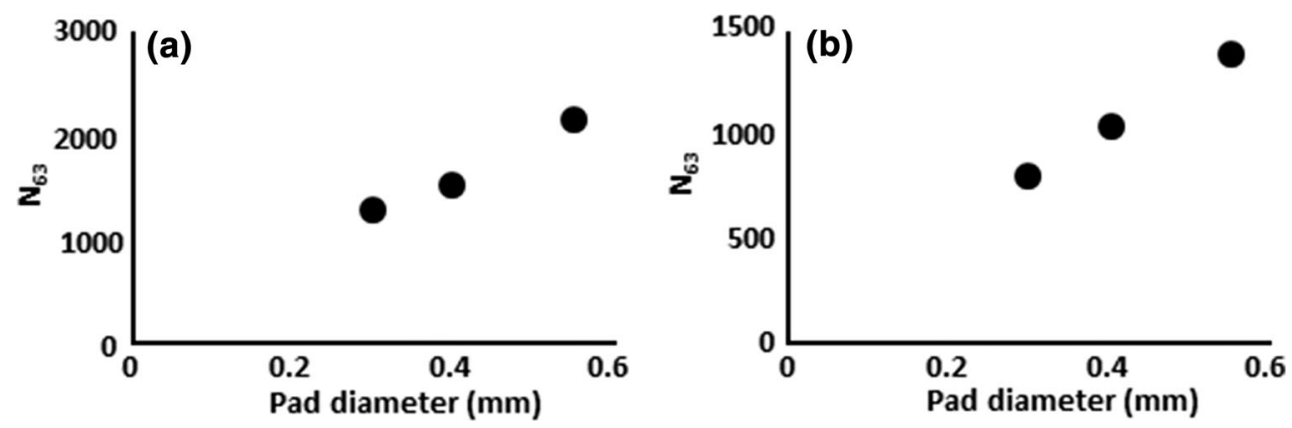

Fig. 12. Characteristic life span in $0 / 100^{\circ} \mathrm{C}$ cycling versus pad diameter for SAC305 joints with sizes and pitch scaled so that the shear strain range was the same. (a) Dwells of $15 \mathrm{~min}$ at both temperature extremes; (b) dwells at $60 \mathrm{~min}$.
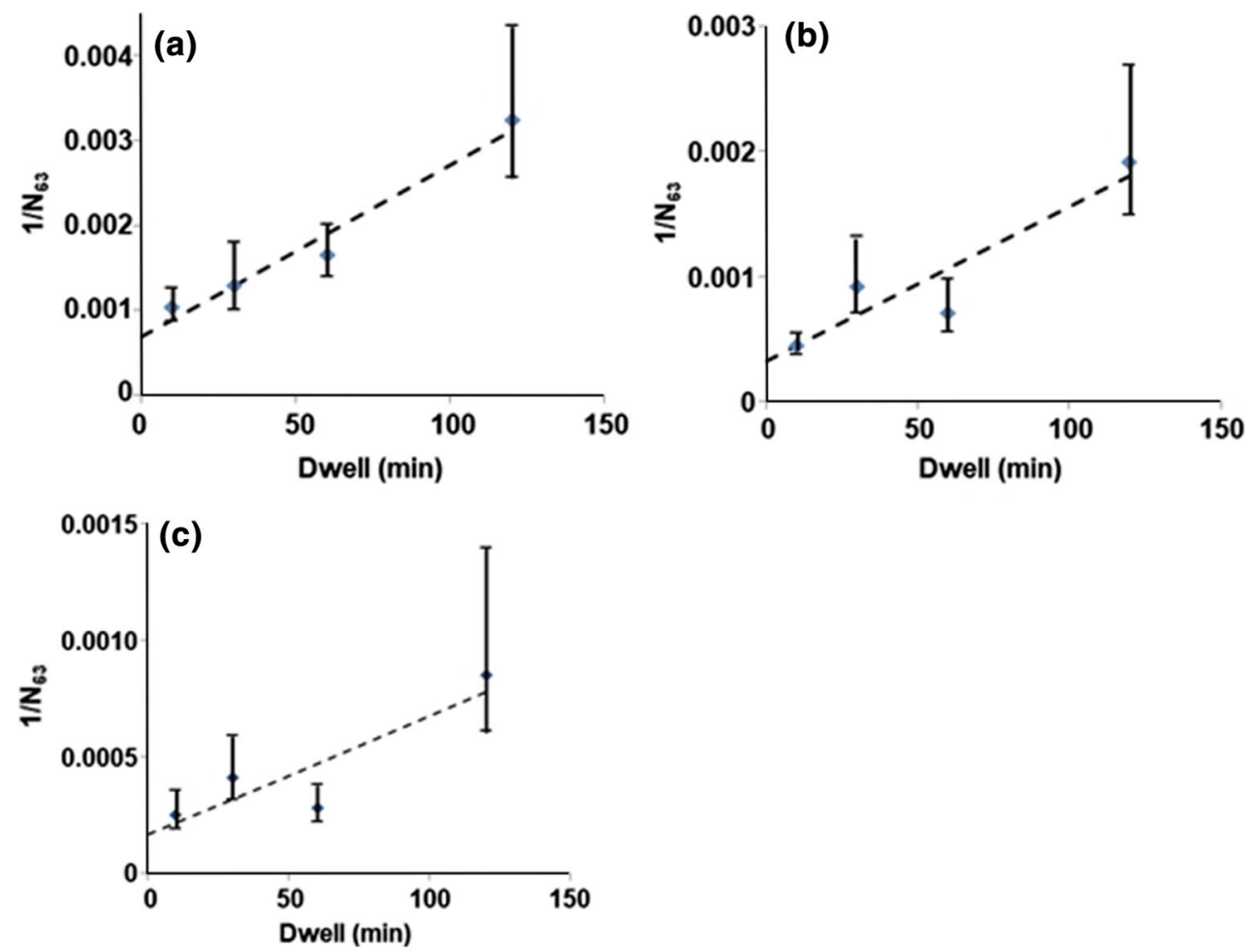

Fig. 13. Inverse of $N_{63}$ values for BGA assemblies with SAC305 joints in $0 / 100^{\circ} \mathrm{C}$ thermal cycling versus dwell time for three different DNP values: (a) $8.9 \mathrm{~mm}$; (b) $6.9 \mathrm{~mm}$; and (c) $5 \mathrm{~mm}$.

Table I. Parameters extracted from fits to Eq. 1

\begin{tabular}{lccc}
\hline Parameter & DNP = 8.9 mm & DNP = 6.9 mm & DNP = 5 mm \\
\cline { 2 - 3 }$\alpha\left(10^{-5} \min ^{-1}\right)$ & 2.0 & 1.2 & 0.5 \\
$\beta\left(10^{-5}\right)$ & 69 & 32 & 17 \\
$\xi(\min )$ & 34 & 26 & 33 \\
\hline
\end{tabular}

at 10-min dwells with $\xi=32 \mathrm{~min}$ here tend to overestimate the average rate of damage, $1 / N_{63}$, with a 60-min dwell. We also measured the characteristic life span, $N_{63}$, of a different set of model assemblies (Fig. 3) in $-40 / 125^{\circ} \mathrm{C}, 0 / 100^{\circ} \mathrm{C}$, and $0 / 80^{\circ} \mathrm{C}$. In this case, the nominal strain ranges were significantly higher. The representative error bars are large but, as in Fig. 14, there is a tendency for the fits through the 15-min data points with $\xi=32 \mathrm{~min}$ to overestimate the $60-\mathrm{min}$ 


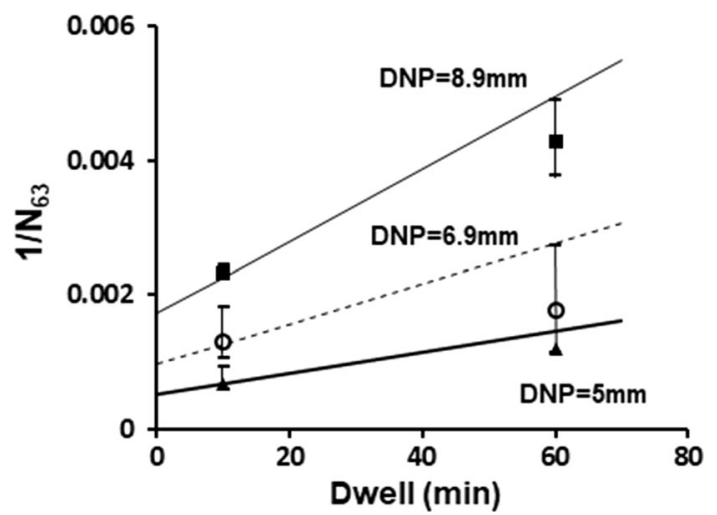

Fig. 14. Inverse of $N_{63}$ values for BGA assemblies with SAC305 joints and 3 different DNP values in $-40 / 125^{\circ} \mathrm{C}$ thermal cycling versus dwell time. $\xi=32 \mathrm{~min}$.

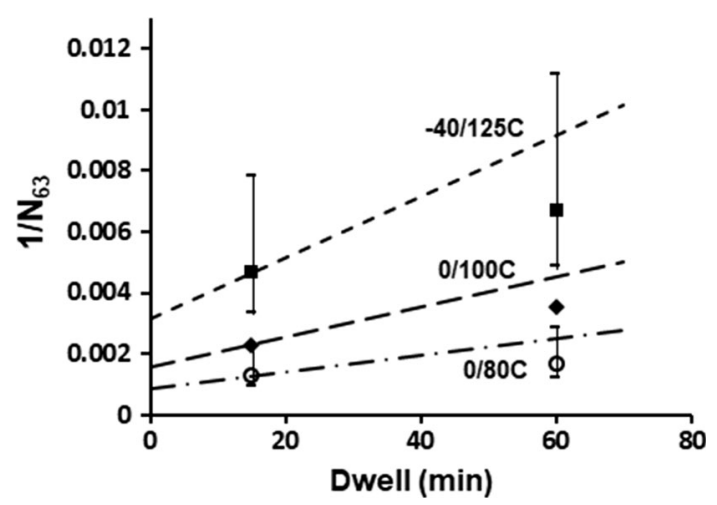

Fig. 15. Inverse of $N_{63}$ values for BGA assemblies with SAC305 solder joints in $0 / 80^{\circ} \mathrm{C}, 0 / 100^{\circ} \mathrm{C}$, and $-40 / 125^{\circ} \mathrm{C}$ thermal cycling with 15-min dwell at low-temperature versus high-temperature dwell time. Fits with $\xi=32 \mathrm{~min}$.

dwell points (Fig. 15), i.e., the damage rate here is also starting to level off as expected.

On the other hand, the linear relationship would be expected to hold up to longer dwell times at lower temperatures where $K(T)$ is lower, so Eq. 4 with $\xi=32 \mathrm{~min}$ is expected to apply to the extrapolation of common accelerated test results to many longterm service conditions.

Figure 16 shows the $\alpha$ values in Table I and those extracted from the fits in Fig. 14 versus the DNP of the corner joints in each assembly. Separate fits to the $-40 / 125^{\circ} \mathrm{C}$ and $0 / 100^{\circ} \mathrm{C}$ data both suggested a variation with $\mathrm{DNP}^{2.2}$, independently of the maximum dwell temperature $T_{\max }$. This is in excellent agreement with the trends discussed above. Anyway, ignoring effects of the minimum temperature, the difference between the fits when $T_{\max }$ increases from $100^{\circ} \mathrm{C}$ to $125^{\circ} \mathrm{C}$ would be consistent with an effective activation energy on the order of $0.5 \mathrm{eV}$. A more accurate estimate was achieved for the three temperatures in Fig. 15. The variation of the $\alpha$ values with $T_{\max }$ would be consistent with an activation energy of $0.37 \mathrm{eV}$. This would also be consistent with a previously reported ratio of 2 in

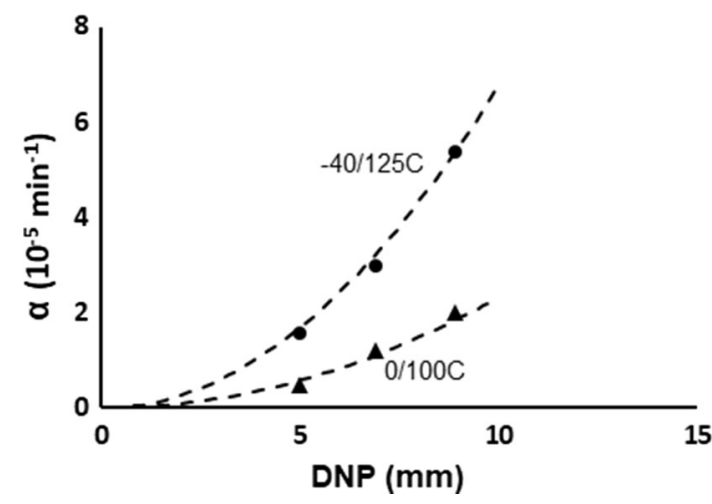

Fig. 16. $\alpha$ values from Table I and fits in Fig. 14 versus distance to neutral point (DNP). Broken curve fits both show variation with DNP $^{2.2}$.

lifetimes for cycling of 3 smaller solder joint sizes in $-40 / 125^{\circ} \mathrm{C}$ and $0 / 100^{\circ} \mathrm{C} .{ }^{49}$

Preliminary results published elsewhere ${ }^{47}$ ) suggest an activation energy on the order of $0.45 \mathrm{eV}$ for diffusion creep in thermally cycled SAC305 joints, so we expect $\Delta W$ to vary as $e^{0.45 / k T}$ in the linear regime and slower beyond that (Eq. 22). An effective activation energy of $0.37 \mathrm{eV}$ for $\Delta W *$ $f\left(T_{\text {max }}\right)$ thus points to an actual activation energy of about $0.82 \mathrm{eV}$ for $f\left(T_{\max }\right)$. This is within the range of reported activation energies of $0.62-$ $0.88 \mathrm{eV}$ for dislocation creep and thus for increase of dislocations, ${ }^{29,50,56,57}$ which may be the ratelimiting mechanism for dislocation cell and subgrain rotation.

All of this leads us to a final approximate expression for the damage function contribution in Eq. 2:

$$
N_{\text {recr }}=\Phi_{1} * L * e^{\Delta E r / k T} / \Delta W
$$

where $\Delta \mathrm{E}_{r}=0.82 \mathrm{eV}$ and $\Phi_{1}$ is a constant.

\section{Precipitate Coarsening}

As mentioned above, the rate of recrystallization is assumed to be zero whenever the driving pressure falls below the Zener pinning pressure. ${ }^{45}$ The driving pressure is proportional to the density of mobile dislocations ${ }^{38}$ which varies with the square of the stress. ${ }^{58}$ The pinning pressure is proportional to the volume fraction, $F_{\text {prec }}$, and inversely proportional to the average precipitate size, $d_{\mathrm{p}}{ }^{26}$, i.e., it decreases as the precipitates coarsen. It follows that the threshold size above which recrystallization commences can be approximated as

$$
d_{\mathrm{thr}}\left(\sigma_{o}\right)=\Phi_{2} * \sigma_{o}^{-2} * F_{\mathrm{prec}}
$$

where $\sigma_{o}\left(T_{\max }\right)$ is the stress at the beginning of the high-temperature dwell and $\Phi_{2}$ is a constant.

If the initial size, $d_{o}$, of the $\mathrm{Ag}_{3} \mathrm{Sn}$ platelets is smaller than this, the number of cycles, $N_{\text {ini, }}$ required for it to reach $d_{\text {thr }}$ can be estimated based 
on a conventional expression for two-dimensional coarsening

$$
d_{\mathrm{thr}}^{2}=d_{o}^{2}+K^{\prime} \cdot C_{\mathrm{Ag}} \cdot D_{\mathrm{Ag}} \cdot \frac{t_{\mathrm{eff}}}{T} \cdot N_{\mathrm{ini}}
$$

where the 'effective dwell time', $t_{\text {eff }}$, includes a term, $t_{\text {ramp }} \cdot\left(1+\phi_{o} \cdot \dot{\varepsilon}_{\text {in }}\right)$, to account for strain-enhanced coarsening during the heating and cooling ramps. ${ }^{39,48,50}$ Here, $\dot{\varepsilon}_{\text {in }}$ is the inelastic shear strain rate in the ramp, $C_{\mathrm{Ag}}$ is the equilibrium solubility of $\mathrm{Ag}$ in the solder, $D_{\mathrm{Ag}}$ is the diffusivity of $\mathrm{Ag}$ in the fastest direction in Sn, $T$ is the absolute temperature, and $K^{\prime}$ and $\varphi_{o}$ are constants. Kumar et al. ${ }^{50}$ calculated the effective ramp time, $t_{\text {ramp }}$, from an integral over the dependent coarsening rate in the ramp.

This means that the number of cycles until the onset of the recrystallization process (dislocation cell coalescence and rotation) can be approximated as

$$
N_{\text {ini }}=\frac{\frac{\Phi_{2}^{2} \cdot F_{\text {prec }}^{2} \cdot \sigma_{o}^{-4}-d_{o}^{2}}{K^{\prime} C_{\mathrm{Ag}} \cdot D_{\mathrm{Ag}}} \cdot T}{t_{d}+t_{\mathrm{ramp}} \cdot\left(1+\phi_{o} \cdot \dot{\varepsilon}_{\mathrm{in}}\right)}
$$

Like $N_{\text {recr, }}$, this term increases with decreasing temperature, but whenever the inelastic deformation is dominated by diffusion, the temperature dependencies of $\sigma_{o}$ and $\Delta W$ are the same ("Appendix"), so $\sigma_{o}^{-4}$ varies much faster and $N_{\text {ini }}$ eventually starts to dominate for the lower maximum temperatures and strain rates typical of most service conditions. One indication of significant contributions of $N_{\text {ini }}$ to the characteristic life span, $N_{63}$, is thus a stronger dependence on DNP. As shown and discussed above and in a recent paper, ${ }^{59}$ the number of cycles to recrystallization, $N_{\text {recr }}$, varies with $\mathrm{DNP}^{-\mathrm{n}}$, where $n$ is near 2 . However, Joshi et al. ${ }^{60}$ reported a value of about 2.8 for 0.4 mm-diameter joints on 0.375 -mm pads. In their experiments, the lowest DNP values gave $N_{63}$ in excess of 4000 in $0 / 100^{\circ} \mathrm{C}$ cycling, so it is indeed reasonable to assume that $N_{\mathrm{ini}}$ is a significant factor there.

Another indication of significant contributions of $N_{\text {ini }}$ to the characteristic life span is, of course, an effect of the initial precipitate size, $d_{o}$. Our final experiment was similar to the ones leading to the results in Fig. 12, but included smaller (12 mil) solder balls and pads. The 4 different designs all had 256 joints in a partially depleted area array, but different solder ball sizes were mounted on correspondingly sized contact pads with a pitch scaled so that the shear strain ranges and rates on them were the same in a given cycle. Figure 17 shows the lifetimes in $0 / 100^{\circ} \mathrm{C}$ cycling with 60 -min dwells. Like in Fig. 12, the life span increases linearly with pad diameter above $0.3 \mathrm{~mm}$, consistent with the assumption of a negligible delay in recrystallization. However, the smallest pad diameter, $0.24 \mathrm{~mm}$, led to a disproportionately high characteristic life span.

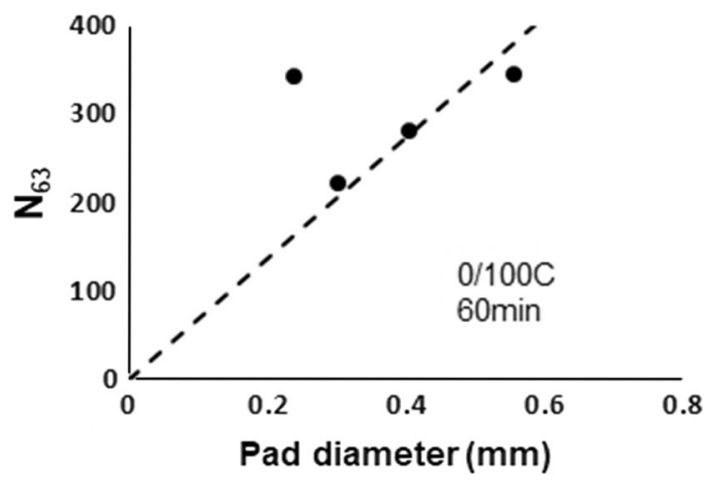

Fig. 17. Characteristic life span versus pad diameter.

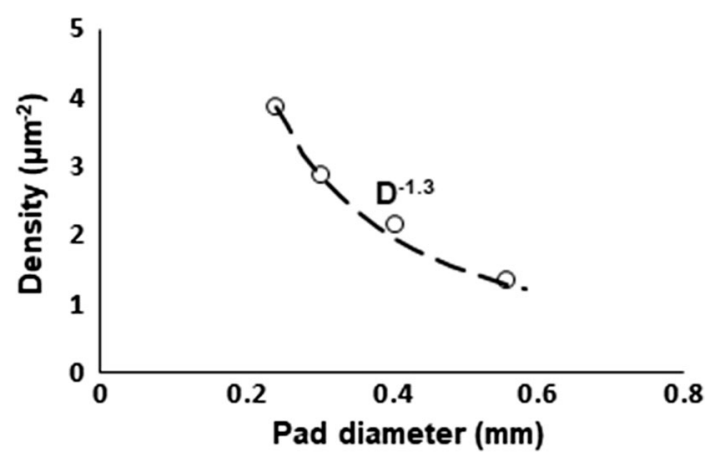

Fig. 18. Number of $\mathrm{Ag}_{3} \mathrm{Sn}$ precipitates per $\mu \mathrm{m}^{2}$ within pseudo-eutectic regions versus pad diameter. Curve: fit to power dependence on diameter.

We conclude that $d_{o}<d_{\mathrm{thr}}\left(\sigma_{o}\right)$ for this pad diameter while $d_{o}>d_{\mathrm{thr}}\left(\sigma_{o}\right)$ for the $0.3-\mathrm{mm}$ pad.

This allows for an estimate of the threshold precipitate size. The initial precipitate sizes and spacings varied systematically with the solder ball and pad size, with the smaller balls undercooling more before solidification after reflow. The average densities within the pseudo-eutectic regions between the Sn dendrites were quantified using a scanning electron microscope. The values varied as the inverse of the pad diameter to a power of 1.3 (Fig. 18) and were readily converted to values for the average spacings, $\lambda^{46}$ Ignoring $\mathrm{Ag}$ in solution, the volume fraction, $F_{\text {prec }}$, of $\mathrm{Ag}_{3} \mathrm{Sn}$ in the solder was calculated to be $\sim 4 \%$ based on a measured volume fraction of $4.7 \%$ in $\mathrm{Sn}-3.5 \% \mathrm{Ag}{ }^{61}$ Finally, image analysis suggested a volume fraction, $F_{\text {eu }}$, of eutectic in the solder of about $50 \%$. Assuming the precipitates to be arranged in a cubic array within the eutectic, the average precipitate sizes were then estimated from

$$
d^{3}=\frac{\pi}{6} \frac{F_{\text {prec }}}{F_{\text {eu }}} \lambda^{3}
$$

This leads to initial precipitate sizes of $0.32 \mu \mathrm{m}$ and $0.27 \mu \mathrm{m}$ for the $0.3-\mathrm{mm}$ and $0.24-\mathrm{mm}$ pads, respectively, and we conclude that the threshold 
$d_{\mathrm{thr}} \sim 0.32 \mu \mathrm{m}$ for this temperature and strain range.

We should, however, not put too much faith in the absolute values at this point. A growth of the average precipitate size from $0.27 \mu \mathrm{m}$ to $0.32 \mu \mathrm{m}$ over $100-200$ cycles with 60 -min dwells at $100^{\circ} \mathrm{C}$ is less than that observed for lower strain rates in previous work. Yin et al. measured average precipitate sizes versus number of $0 / 100^{\circ} \mathrm{C}$ cycles with 10 min dwells ${ }^{12}$ for full-area array packages with 0.5$\mathrm{mm}$ balls on $0.375-\mathrm{mm}$ pads. The initial precipitate size was about $0.4 \mu \mathrm{m}$, in good agreement with the fit in Fig. 18. Sahaym et al. ${ }^{62}$ showed precipitate coarsening to slow down or even reverse temporarily after completion of recrystallization, and most of the data of Yin et al. cover cycling beyond that. However, one small component with a DNP of only $5 \mathrm{~mm}$ did not reach that stage until 2000 cycles. After 1000 cycles, the average precipitate size had grown to $0.53 \pm 0.05 \mu \mathrm{m}$. In the absence of strainenhanced coarsening, Eq. 7, using literature values for the parameters, ${ }^{48}$ would predict a size of $0.51 \mu \mathrm{m}$ in that experiment and growth from $0.27 \mu \mathrm{m}$ to $0.37 \mu \mathrm{m}$ within 100 cycles in our experiment.

Better constitutive relations would be required ${ }^{47}$ for quantitative predictions of $\sigma_{o}\left(T_{\max }\right)$ and attempts to match these to measured precipitate sizes.

\section{DAMAGE ACCUMULATION AND ACCELERATION FACTOR EXPRESSION}

When it comes to the quantitative extrapolation of accelerated test results to 'life in service', significant work remains to calibrate our expression for $N_{\text {ini. }}$. Until that has been accomplished, the best we can offer is a conservative acceleration factor expression based on ignoring that term. How conservative the result is, will of course depend strongly on which parameters were accelerated and by how much. Even rough estimates of the effect, along the lines of the above, usually require constitutive relations and current ones are seriously misleading. ${ }^{47}$

Focusing on $N_{\text {recr }}$, until better constitutive relations have been established we cannot calculate the work, $\Delta W$, directly. Instead, as in the previous section, we approximate it as $\dot{W}_{\mathrm{ss}} *\left(\xi+t_{d}\right)$, where $\xi=32 \mathrm{~min}$, and take the steady-state rate of work to be proportional to the square of the distance to the neutral point. In extracting an activation energy for the function $f\left(T_{\max }\right)$ we ignored any effects of the minimum temperature, $T_{\min }$, on the work done at $T_{\max }$. However, $T_{\min }$ does have a minor effect on the stress at the maximum temperature and it may also affect the density of dislocations established there as a basis for the ongoing recrystallization at the high temperature. Empirically, we approximate this by an Arrhenius function. Previous work showed life span in $-20 / 100^{\circ} \mathrm{C}$ cycling to be roughly $10 \%$ shorter than life span in $0 / 100^{\circ} \mathrm{C}$, pointing to an

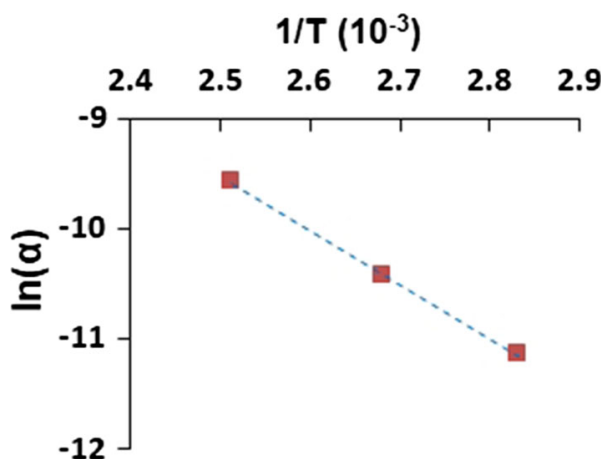

Fig. 19. Arrhenius plot of empirically corrected $\alpha$ values from Fig. 15 suggesting activation energy $\Delta E=0.42 \mathrm{eV}$.

effective activation for this function of $\Delta \mathrm{E}_{\mathrm{lo}}=0.03 \mathrm{eV}$. Using this to correct for the effect of $T_{\text {min }}$ in Fig. 15 finally leads to an Arrhenius plot of the effect of $T_{\max }$ on the $\alpha$ values from the fits (Fig. 19), and a corrected activation energy for the variation of $1 / N_{\text {recr }}$ with $T_{\max }$ of $\Delta \mathrm{E}_{\mathrm{ap}}=0.42 \mathrm{eV}$.

The resulting preliminary approximation.

$N_{\text {recr }}=\Phi * e^{\Delta E_{\mathrm{ap}} / k T_{\mathrm{hi}}} \times e^{-\Delta E_{\mathrm{lo}} / k T_{\mathrm{lo}}} * L /\left\{\mathrm{DNP}^{2} *\left(\xi+t_{d}\right)\right\}$

where $L$ is the joint diameter, $\xi=32 \mathrm{~min}$, and $\Phi$ is a constant, requires, among others, that the stress reaches a maximum during the heating ramp before reaching the maximum dwell temperature ("Appendix"). This assumption breaks down for sufficiently high minimum temperatures so extrapolations to cycles with minimum temperature much above $0^{\circ} \mathrm{C}$ may be conservative. Also, this extrapolation will be conservative (a) for high maximum temperatures when extrapolating to longer dwell times, and (b) when extrapolating to lower strain ranges where precipitate coarsening becomes increasingly important.

\section{Acceleration Factor}

Equation 10 leads us to an expression for the ratio between the number of cycles to failure under simplified use conditions and under accelerated test conditions:

$$
\begin{aligned}
\frac{N_{\text {use }}}{N_{\text {test }}}= & e^{\Delta E_{\text {ap }} / k \cdot\left(\frac{1}{T_{\text {hi }}^{\text {use }}}-\frac{1}{T_{\text {hi }}^{\text {test }}}\right)} \times e^{-\Delta E_{l o} / k \cdot\left(\frac{1}{T_{\text {lo }}^{\text {use }}}-\frac{1}{T_{\text {lo }}^{\text {test }}}\right)} \\
& *\left(\xi+t_{d}^{\text {test }}\right) /\left(\xi+t_{d}^{\text {use }}\right)
\end{aligned}
$$

where both use and test conditions are characterized by fixed cycling parameters.

\section{Damage Accumulation}

Of course, realistic service conditions invariably involve major and ongoing variations in cycling amplitude or, in the case of thermal cycling, in dwell times and temperatures. In the case of isothermal 
cycling, say in vibration, the resulting accumulation of damage and eventual failure cannot be predicted, even approximately, based on results of fixed amplitude cycling tests alone. ${ }^{63-65}$ That is a result of longterm effects ('memory') of amplitude on the material's properties. Ignoring these leads to overestimates of life in service. In the case of thermal cycling, ${ }^{66}$ challenges arise from the dependence of the threshold precipitate size on the stress (Eq. 6). Except for the lack of quantitative parameters, the complete picture established above lends itself readily to the assessment of damage accumulation under any kind of thermal cycling with varying dwell times and temperatures. Future publications will discuss the use in the definition of accelerated test protocols and the interpretation of test results. Meanwhile, to the extent that $N_{\text {ini }}$ can be ignored, Miner's rule of linear damage accumulation should apply; so, Eq. 10 is still conservative.

\section{DISCUSSION AND SUMMARY}

Mattila and co-workers have proposed a picture involving only one crack growth mechanism. ${ }^{21}$ According to this, the rate of crack growth is strongly accelerated by the formation of a network of grain boundaries (recrystallization), but at sufficiently low stresses, recrystallization does not occur and a crack eventually progresses through the $\mathrm{Sn}$ lattice instead. In contrast, we propose two competing mechanisms. Isothermal cycling does not lead to extensive recrystallization, and failure does eventually occur by the growth of a crack through the lattice. ${ }^{64,65}$ The same mechanism is also active in thermal cycling, leading to an almost immediate initiation of a transgranular crack. ${ }^{11}$ However, the dominant mechanism is the formation and ongoing rotation of new grains leading to ever greater misorientation and eventually crack growth. ${ }^{24,26}$ The transgranular crack growth mechanism may involve local recrystallization near the crack tip, but from a modeling perspective, at least it is completely different. In isothermal cycling, failure by transgranular crack growth can be predicted based on the total inelastic work per cycle, ${ }^{64,65}$ whereas intergranular crack growth in thermal cycling clearly cannot. The very different dependencies on cycling parameters may explain why one thermal cycling test under conditions approaching those typical of long-term service led to major recrystallization, ${ }^{22}$ while another did not. ${ }^{21}$ Work is ongoing to address transgranular crack growth in combinations of thermal cycling and vibration, but the present work is focused on recrystallization.

According to Mattila and co-workers as well as Bieler and co-workers, the evolution of the microstructure in thermal cycling starts with gradual coalescence and rotation of dislocation structures, but eventually the stored deformation energy becomes high enough to allow for discontinuous recrystallization. ${ }^{20,67}$ Together, these two mechanisms account for the observed continuous ranges of misorientation angles, but the energy deposition and storage is much greater at low temperatures, whereas we have shown (above) that the rate of recrystallization is dominated by the very small part of the overall work done during the hightemperature dwell.

We thus propose that the life span of realistic $\mathrm{SnAgCu}$ solder joints in thermal cycling can be predicted based on the rate of continuous recrystallization of the $\mathrm{Sn}$ grains. The completion of a continuous network of high-angle grain boundaries across the high-strain region in a joint requires the repeated alternation between a 'high' and a 'low' temperature. The low temperature allows for the establishment of a somewhat stable dislocation cell structure. This structure approaches a steady-state after, for example, $10-15 \mathrm{~min}$ at $0^{\circ} \mathrm{C}$ and the fatigue life span is not very sensitive to extensions of the low-temperature dwell beyond that. Loading during a subsequent high-temperature dwell leads to the ongoing multiplication and stabilization of dislocations on this structure and the simultaneous coalescence and rotation of the cells. While the lowtemperature structure is critical for the temporary stabilization of the dislocations generated at the higher temperature, the latter dominate the overall recrystallization per cycle. The effective rate of dynamic recrystallization at any time during the high-temperature dwell is controlled by a balance between the creation of dislocations and the coalescence and rotation of the resulting cells. Indications are that the amount of recrystallization per cycle scales with the inelastic work done during the hightemperature dwell.

The onset of the coalescence and rotation of the dislocation structures is delayed by pinning on the secondary precipitates until their spacing has increased, through cycling-enhanced coarsening, to a threshold value that is higher for lower-strain ranges.

Over the years, Bieler and co-workers have conducted a range of microstructural studies, in several cases characterizing the same solder joint after different levels of thermal cycling. ${ }^{23,67-69} \mathrm{As}$ expected, the behavior of the highly anisotropic joints is seen to vary strongly with orientation. Most recently, an experiment also including long periods of room-temperature aging between cycling seems to cast doubt on the assumption of a simple correlation between the general level of recrystallization and cracking. ${ }^{67}$ The coarsening of precipitates in aging led to easier recrystallization in continued cycling afterwards. The resulting grains were smaller and less stable but crack growth was faster. This is in contrast to previous experiments in which we interrupted cycling of $95.5 \mathrm{Sn} 3 \mathrm{Ag} 0.5 \mathrm{Cu}$-based BGA assemblies at regular intervals and annealed them for $50 \mathrm{~h}$ at $70^{\circ} \mathrm{C}$ before continuing, leading to major delays in both recrystallization and crack evolution. ${ }^{70}$ Anyway, the emerging picture still 
appears to point to a direct correlation between cracking and the formation of high-angle boundaries. It is, however, not obvious to which extent this picture is going to be consistent with the observed strong effects of the high temperature and the dwell there, the much weaker effect of the low temperature and the dwell there, and the even weaker effect of heating and cooling rates.

\section{CONCLUSION}

The proposed mechanistic picture leads to an approximation for the characteristic life span of typical $\mathrm{SnAgCu}$ solder joints in thermal cycling as the sum of two terms. The number of cycles, $N_{\text {ini }}$, for the precipitate spacing to reach the threshold dominates at the low strains is typical of long-term service conditions, but is negligible in highly accelerated testing. Approximate expressions for this and the number of cycles, $N_{\text {recr }}$, to completion of recrystallization and crack growth offer a solid mechanistic basis for the understanding of what determines the thermal fatigue life span of a $\mathrm{SnAgCu}$ solder joint, including effects of solder volume, pad sizes and finishes, and process parameters. ${ }^{46,59}$ This leads to recommendations with respect to thermal cycling test protocols and the interpretation of test results for different types of applications. $^{3}$

Further work is required to calibrate the expression for $N_{\text {ini }}$, and the quantitative prediction of $N_{\text {recr }}$ is inhibited by the lack of appropriate constitutive relations for $\mathrm{SnAgCu}$ in thermal cycling. Until these limitations have been resolved, we offer a practical but conservative acceleration factor expression. Use of this together with Miner's rule of linear damage accumulation should also provide for conservative predictions of life span under realistic service conditions where dwell times and temperatures vary on an ongoing basis.

\section{ACKNOWLEDGEMENTS}

This research was supported by the U. S. Department of Defense through the Strategic Environmental Research and Development Program (SERDP), by the National Science Foundation under Grant No. DMR 1206474, by the Integrated Electronics Engineering Center (IEEC), and by the AREA Consortium.

\section{APPENDIX}

Rather than a large number of FEM-based simulations with different potential constitutive relations, highly simplified calculations were employed in order to illustrate and predict generic trends. For this purpose, we first of all consider the evolution of representative stress and strain in a corner solder joint during a thermal cycle after 'stabilization', i.e., after the first $4-5$ cycles. At any given time, the total (nominal) strain is the sum of the inelastic strain in the solder and the combined elastic strains in the solder, component and PCB. Assuming an effective stiffness $E_{\text {eff }}$ of the latter combination, the total elastic strain is $\varepsilon_{\mathrm{el}}=\sigma / E_{\text {eff }}$ and ignoring primary or transient creep, the rate of inelastic deformation of the solder joint is simply expressed as

$$
\dot{\varepsilon}_{\text {in }}=K(T) * \sigma^{n}
$$

where $\sigma$ is the stress, $K(T)$ is only a function of temperature, and the exponent ' $n$ ' is a constant. This means that the total inelastic strain rate

$$
\dot{\varepsilon}_{\text {tot }}=\frac{\dot{\sigma}}{E_{\text {eff }}}+K(T) \cdot \sigma^{n}
$$

We ignore any cycling-induced evolution of the deformation properties and define the stress during the high-temperature dwell to be positive, which means that it is negative during the low-temperature dwell. During the heating ramp, the stress then increases, going through zero and rapidly reaching a level where the inelastic deformation dominates completely, i.e.,

$$
\sigma(T)=\left[\frac{\dot{\varepsilon}_{\text {tot }}(\mathrm{ramp})}{K(T)}\right]^{\frac{1}{n}}
$$

This is because $K(T)$ increases with temperature the stress decreases after that.

This includes the stress, $\sigma_{0}$, at the beginning of the high-temperature dwell. For a given heating rate, the total strain rate is proportional to the $\mathrm{DNP}$, so the stress at the end of a given heating ramp

$$
\sigma_{o}=\left[\frac{H \cdot \mathrm{DNP}}{K(T)}\right]^{\frac{1}{n}}
$$

where $H$ is a constant. The nominal inelastic strain rate during the dwell is of course zero, so Eq. 13 now gives

$$
\dot{\sigma}=-K(T) \cdot E_{\mathrm{eff}} \cdot \sigma^{n}
$$

\section{Current Constitutive Relations}

Most current expressions are consistent with a value of $n=6$, in which case Eq. 16 to

$$
\sigma(t)=\left(\sigma_{o}^{-5}+5 K(T) \cdot E_{\mathrm{eff}} \cdot t\right)^{\frac{-1}{5}}
$$

during the high-temperature dwell. The corresponding inelastic work follows by integrating $\sigma \cdot \mathrm{d} \varepsilon_{\text {in }}$, where $\mathrm{d} \varepsilon_{\text {in }}=K \cdot \sigma^{6} \cdot \mathrm{d} t$ :

$$
\Delta W=\frac{5^{\frac{6}{5}}}{2 E}\left\{\sigma_{o}^{2}-\left[\sigma_{o}^{-5}+5 K \cdot E_{\mathrm{eff}} \cdot t_{d}\right]^{\frac{-2}{5}}\right\}
$$

Here, $t_{d}$ is the duration of the high-temperature dwell. Taylor expansion of this and insertion of $\sigma_{o}$ (Eq. 15) finally leads to 
$\Delta W=5^{\frac{1}{5}} K^{\frac{-1}{6}}\left\{\mathrm{DNP}^{\frac{7}{6}} \cdot t_{d}-17.5 K^{\frac{1}{6}} \cdot E_{\text {eff }} \cdot H^{2} \cdot \mathrm{DNP}^{2} \cdot t_{d}^{2}+\cdots\right\}$

and thus a variation of the high-temperature work with the DNP that starts out slightly faster than linear for very short dwells but rapidly becomes weaker. FEM calculations reported elsewhere led to a power of about $0.6^{3}$ for a similar value of $n$.

\section{New Constitutive Relations}

As discussed above, recent ${ }^{47}$ and forthcoming publications argue for dominant contributions from a different creep mechanism leading to a variation of inelastic strain rates with the stress to a power of $n=1$. Inserting that into Eq. 16 and solving leads first to

and then

$$
\sigma(t)=\sigma_{o} \cdot e^{-K \cdot E_{\mathrm{eff}} \cdot t}
$$

$$
\Delta W=\frac{\sigma_{o}^{2}}{2 E} \cdot\left\{1-e^{-2 K \cdot E_{\text {eff }} \cdot t_{d}}\right\}
$$

Taylor expansion of this and insertion of $\sigma_{o}$ (Eq. 15) then leads to

$$
\Delta W=K^{-1} \cdot H^{2} \cdot \mathrm{DNP}^{2} \cdot\left\{t_{d}-K \cdot E_{\mathrm{eff}} \cdot t_{d}^{2}+\frac{2}{3} K^{2} \cdot E_{\mathrm{eff}}^{2} v t_{d-\ldots}^{3} \ldots\right\}
$$

The scaling with $\mathrm{DNP}^{2}$ for all dwell times and temperatures is in excellent agreement with experimental observations. ${ }^{2}$

We note for later use that (1) $\Delta \mathrm{W}$ starts out as a linear function of dwell time and (2) the temperature dependence of $\Delta \mathrm{W}$ is contained in $K(T)$, i.e., the effective activation energy is that of diffusion.

\section{REFERENCES}

1. L. Wentlent, L. Yin, M. Meilunas, B. Arfaei, and B. Borgesen, in Proceedings of SMTA International Conference, p. 101, 2011.

2. P. Borgesen, E. Al-Momani, and M. Meilunas, in Proceedings of SMTA, 2009.

3. P. Borgesen, J. Jiang, L. Wentlent, M. Meilunas, R. Sivasubramony, L. E. Alvarez, T. Alghoul, and C. Greene, in Proceedings of SMTA International, Rosemont, IL, USA, 2017.

4. L. Lehman, Y. Xing, T. Bieler, and E. Cotts, Acta Mater. 58, 3546 (2010).

5. D.W. Henderson, J.J. Woods, T.A. Gosselin, J. Bartelo, D.E. King, T.M. Korhonen, M.A. Korhonen, L.P. Lehman, E.J. Cotts, S.K. Kang, P. Lauro, D.-Y. Shih, C. Goldsmith, and K.J. Puttlitz, J. Mater. Res. 19, 1608 (2004).

6. S. Terashima, T. Kobayashi, and M. Tanaka, Sci. Technol. Weld. Join. 13, 732 (2008).

7. S. Terashima, K. Takahama, M. Nozaki, and M. Tanaka, Mater. Trans. 45, 1383 (2004).

8. U. Telang, R. Bieler, A. Zamiri, and F. Pourboghrat, Acta Mater. 55, 2265 (2007).

9. J. Sundelin, S. Nurmi, and T. Lepistö, Mater. Sci. Eng. A 474, 201 (2008).

10. T. Mattila, and J. Kivilahti, IEEE Trans. Compon. Packag. Manuf. Technol. 33, 629 (2010).
11. A. Qasaimeh, S. Lu, and P. Borgesen, in Components Packaging Manufacturing Technology Conference, 2011.

12. L. Yin, L. Wentlent, L. Yang, B. Arfaei, A. Qasaimeh, and P. Borgesen, J. Electron. Mater. 41, 241 (2012).

13. L. Yin, M. Meilunas, B. Arfaei, L. Wentlent, and P. Borgesen, in Proceedings of Electronic Components Technology Conference, 2012.

14. A. Dasgupta, C. Oman, D. Barker, and M. Petit, AMSE J. Electron. Packag. 114, 152 (1992).

15. A. Qasaimeh, Y. Jaradat, L. Wentlent, L. Yang, L. Yin, B. Arfaei, and P. Borgesen, in Electronic Components and Technology Conference, pp. 1775-1781, 2011.

16. A. Schubert, R. Dudek, E. Auerswald, M. Gollbardt, and H. Reichl, Components Packaging Manufacturing Technology Conference, p. 603, 2003.

17. A. Syed, in Proceedings of Electronic Components and Technology Conference, Las Vegas, NV, USA, USA, 2004.

18. H. S. Ng, T. Payoh, T. Y. Tee, K. Y. Goh, J. Luan, T. Reinikainen, and A. Kujala, in Proceedings of Components Packaging Manufacturing Technology Conference, Lake Buena Vista, Fl, USA, 2005.

19. C. Basaran, and C.-Y. Yan, J. Electron. Packag. 120, 379 (1998).

20. D. Chan, L. Subbarayan, and L. Nguyen, J. Electron. Mater. 41, 398 (2012).

21. J. Hokka, T.T. Mattila, H. Xu, and M. Paulasto-Krockel, J. Electron. Mater. 42, 963 (2013).

22. B. Arfaei, S. Mahin-Shirazi, S. Joshi, M. Anselm, P. Borgesen, E. Cotts, J. Wilcox, and R. Coyle, in Proc. Electron. Compon. Technol. Conf., Las Vegas, NV, USA, 2013.

23. T. Bieler, P. Borgesen, Y. Xing, L. Lehman, and E. Cotts, in Pb-Free and RoHS-Compliant Materials and Processes for Microelectronics, 2007, C.A Handwerker, K. Suganuma, H.L. Reynolds, J. Bath, eds, MRS Spring Meeting.

24. T.R. Bieler, B. Zhou, L. Blair, A. Zamiri, P. Darbandi, F. Pourboghrat, T.-K. Lee, and K.-C. Liu, J. Electron. Mater. 41, 283 (2012).

25. B. Arfaei, Y. Xing, J. Woods, J. Wolcott, P. Tumne, P. Borgesen, and E. Cotts, in Proceedings Electronic Components and Technology Conference, 2008.

26. B. Zhou, T.R. Bieler, T.-K. Lee, and K.-C. Liu, J. Electron. Mater. 39, 2669 (2010).

27. R.D. Doherty, D.A. Hughes, F.J. Humpreys, J.J. Jonas, D.J. Jensen, M.E. Kassner, W.E. King, T.R. McNelley, H.J. McQueen, and A.D. Rollett, Mater. Sci. Eng. 238, 219 (1997).

28. R.W. Vook, Acta Met. 12, 197 (1964).

29. R. Madec, B. Devincre, and L.P. Kubin, Scr. Mater. 47, 689 (2002).

30. M. Kerr, and N. Chawla, Acta Mater. 52, 4527 (2004).

31. G. Cuddalorepatta, A. Dasgupta, and K. Holdermann, in Proceedings of IMECE 2008, Boston, MA, 2008.

32. A. Mayyas, L. Yin, and P. Borgesen, Proc. ASME Int., p. $319,2009$.

33. A. Qasaimeh, Ph.D. Dissertation, Binghamton University, May 2012.

34. T. Korhonen, L. Lehman, M. Korhonen, and D. Henderson, J. Electron. Mater. 36, 173 (2007).

35. P. Borgesen, L. Yang, A. Qasaimeh, L. Yin, and M. Anselm, in Proceedings of SMTA PanPac Conference, 2013.

36. B. Arfaei, M. Anselm, S. Joshi, S. Mahin-Shirazi, E. Cotts, P. Borgesen, J. Wilcox, and R. Coyle, in Proceedings SMTAI, Rosemont, IL, 2013.

37. D. Schmitz, S. Shirazi, L. Wentlent, S. Hamasha, L. Yin, A. Qasaimeh, and P. Borgesen, in Proceedings of Components, Packagings Manufacturing Technology, Orlando, FL, USA, 2014.

38. F.J. Humphreys, and M. Hatherly, Recrystallization and Related Annealing Phenomena (Oxford: Pergamon Press, 1995).

39. I. Dutta, J. Electron. Mater. 32, 201 (2003).

40. J. Li, T.T. Mattila, and J.K. Kivilahti, J. Electron. Mater. 39, 77 (2010). 
41. J. Li, H. Xu, T.T. Mattila, J.K. Kivilahti, T. Laurila, and M. Palasto-Krockel, Comput. Mater. Sci. 50, 690 (2010).

42. A.D. Rollette, and D. Raabe, Comput. Mater. Sci. 21, 69 (2001).

43. X. Song, and M. Rettenmayr, Mater. Sci. Eng. 332, 153 (2002).

44. Q. Yu, and S.K. Esche, J. Mater. Process. Technol. 169, 493 (2005).

45. F.J. Humphreys, and M.G. Ardakani, Acta Mater. 44, 2717 (1996).

46. S. Shirazi, L. Yin, S. Khasawneh, L. Wentlent, and P. Borgesen, in Proceedings of Components, Packaging, and Manufacturing Technology, San Diego, CA, USA, 2015.

47. T. Alghoul, D. Watson, N. Adams, S. Khasawneh, F. Batieha, C. Greene, and P. Borgesen, in 66th Electronic Components and Technology Conference, 2016.

48. P. Borgesen, E. Cotts, and I. Dutta, in SERDP Grant, Project WP-1752, 2015.

49. H. Song, J. Morris, and F. Hua, JOM 54, 30 (2002).

50. P. Kumar, Z. Huang, S. Chavali, D. Chan, I. Dutta, G. Subbarayan, and V. Gupta, IEEE Trans. Compon. Packag. Manuf. Technol. 2, 256 (2012).

51. M. Motalab, Z. Cai, S. P., and P. Lall, in 13th IEEE Intersociety Conference on Thermal Thermomechanical Phenom Electronics System, San Diego, CA, USA, 2012.

52. S. Wiese, F. Feustel, and E. Meusel, Sens. Actuators A 99, 188 (2002).

53. M. Amagai, M. Watanabe, M. Omiya, K. Kishimoto, and T. Shibuya, Microelectron. Reliab. 42, 951 (2002).

54. M. Pei, and J. Qu, in Proc. Int. Symp. Adv. Packag. Mater.: Processes, Prop. Interfaces, Irvine, CA, USA, USA, pp. 4549, 2005.

55. H. Ng, T. Tee, K. Goh, J. Luan, T. Reinikainen, E. Hussa, and A. Kujala, in Proceedings of Components Packaging Manufacturing Technology, Lake Buena Vista, FL, USA, 2005.
56. M.D. Mathew, H. Yang, S. Movva, and K.L. Murty, Metall. Mater. Trans. 36, 99 (2005).

57. I. Dutta, C. Park, and S. Choi, Mater. Sci. Eng. 379, 401 (2004).

58. A.S. Argon, Scr. Metall. 4, 1001 (1970).

59. P. Borgesen, S. Hamasha, L. Wentlent, D. Watson, and C. Greene, in Proceedings of SMTA PanPac Conference, Big Island, HI, USA, 2016.

60. S. Joshi, B. Arfaei, A. Singh, M. Gharaibeh, M. Obaidat, A. Alazzam, M. Meilunas, L. Yin, M. Anselm, and P. Borgesen, in Proceedings of SMTAI, Rosemont, IL, 2012.

61. E.A. Brandes, Smithells Metals Reference Book, 7th ed. (London: Butterworth, 1992).

62. U. Sahaym, B. Talebanpour, I. Dutta, P. Kumar, and P. Borgesen, IEEE Trans. Compon. Packag. Manuf. Technol. 3, 1868 (2013)

63. S. Hamasha, A. Qasaimeh, Y. Jaradat, and P. Borgesen, IEEE Trans. Compon. Packag. Manuf. Technol. 5, 1292 (2015).

64. A. Qasaimeh, S. Hamasha, Y. Jaradat, and P. Borgesen, J. Electron. Packag. 137, 021012 (2015).

65. F. Batieha, S. Hamasha, Y. Jaradat, L. Wentlent, A. Qasaimeh, and P. Borgesen, in Electronic Components and Technology Conference, 2015.

66. P. Borgesen, S. Hamasha, M. Obaidat, V. Raghavan, X. Dai, M. Meilunas, and M. Anselm, Microelectron. Reliab. 53, 1587 (2013).

67. Q. Zhou, B. Zhou, T.-K. Lee, and T. Bieler, J. Electron. Mater. 45, 3013 (2016).

68. B. Zhou, T. Bieler, T.-K. Lee, and W. Liu, J. Electron. Mater. 42, 319 (2013).

69. B. Zhou, Q. Zhou, T. Bieler, and T.-K. Lee, J. Electron. Mater. 44, 895 (2015).

70. P. Borgesen, L. Yang, B. Arfaei, L. Yin, B. Roggeman, and M. Meilunas, in SMTA Proceedings of Technology Program - Pan Pacific Microelectronics Symposium, 2011. 